\title{
Immune related gene expression of parasite-resistant sheep during a Haemonchus contortus infection
}

\author{
Karen Nicole Sommers \\ West Virginia University
}

Follow this and additional works at: https://researchrepository.wvu.edu/etd

\section{Recommended Citation}

Sommers, Karen Nicole, "Immune related gene expression of parasite-resistant sheep during a Haemonchus contortus infection" (2014). Graduate Theses, Dissertations, and Problem Reports. 368. https://researchrepository.wvu.edu/etd/368

This Thesis is protected by copyright and/or related rights. It has been brought to you by the The Research Repository @ WVU with permission from the rights-holder(s). You are free to use this Thesis in any way that is permitted by the copyright and related rights legislation that applies to your use. For other uses you must obtain permission from the rights-holder(s) directly, unless additional rights are indicated by a Creative Commons license in the record and/ or on the work itself. This Thesis has been accepted for inclusion in WVU Graduate Theses, Dissertations, and Problem Reports collection by an authorized administrator of The Research Repository @ WVU. For more information, please contact researchrepository@mail.wvu.edu. 


\title{
Immune related gene expression of parasite-resistant sheep during a Haemonchus contortus infection
}

\author{
Karen Nicole Sommers
}

Thesis submitted

to the Davis College of Agriculture, Natural Resources \& Design

at West Virginia University

in partial fulfillment of the requirements for the degree of

Master of Science in

Animal Physiology

Scott A. Bowdridge, Ph.D., Chair

Vagner A. Benedito, Ph.D.

Jianbo Yao, Ph.D.

Division of Animal and Nutritional Sciences

Morgantown, West Virginia

2014

Keywords: Interleukin 4; St. Croix sheep; Haemonchus contortus

(C) 2014 Karen Nicole Sommers 


\title{
Abstract \\ Immune related gene expression of parasite-resistant sheep during a Haemonchus contortus infection
}

\author{
Karen Nicole Sommers
}

Gastrointestinal nematode parasitism is a top health concern for sheep producers worldwide as traditional means of treatment are becoming less effective. Haemonchus contortus is of particular interest because it feeds on blood, causing significant pathological problems in the host. Certain breeds of sheep, like St. Croix, are more naturally resistant to parasitism. However, the underlying mechanisms that result in resistance are not fully understood. The following two experiments evaluated qPCR differential gene expression during the first ten days of a challenge $H$. contortus infection from lymph node and abomasal tissues. Experiment 1 evaluated 24 St. Croix hair lambs and 24 Crossbred wool lambs across four experimental days $(0,3,5$, and 7$)$. Wool animals expressed higher levels of genes associated with tissue remodeling, wound healing, and inflammation, but no expression of key Th2 cytokines. Hair sheep expressed genes more closely related to Th2 immune responses. Experiment 2 assigned 12 St. Croix hair lambs and 12 Suffolk crossbred wool lambs into two groups: naïve control and day 10 challenge. No genes were differentially up-regulated in hair animals. Wool animals, however, expressed Th2 genes such as interleukin-4 and arginase-1. Results from these two experiments indicate an adaptive immune response as early as 3 days post challenge infection in hair sheep. Thus, the rapid protective immunity generation of parasite-resistant hair sheep is a key difference by which these animals reduce larval load and prevent establishment of adult parasites. 


\section{Acknowledgements}

The completion of this thesis would not have been possible without the help, support, and guidance of a small village of people. The first is my advisor, Dr. Scott Bowdridge. I am so appreciative for the opportunities he has given me, starting that serendipitous day where he agreed to let me do some undergraduate research. He is a brilliant scientist who pushed my abilities further than I ever thought possible and for that I am ever indebted.

The other members of my committee have been integral to my graduate experience. Both Dr. Jianbo Yao and Dr. Vagner Benedito had high expectations that pushed and inspired me to be a better geneticist. It is through their instruction that I have gained the confidence to give advice and teach others about qPCR and other genetic techniques.

My graduate life would not be complete without the help of all my coworkers in Residential Education. These people have played a consistent roll in making me a better leader and their friendships have made my experience at WVU truly unforgettable. I also have to acknowledge the efforts of my lab mates: Crista Crawford, Megan Graham, Rush Holt, Jesica Jacobs, and Rebecca Price. These folks consistently helped with early morning sample collection and processing throughout my project, all while providing some much needed comic relief.

It goes without saying that the love and encouragement provided to me by my family could never be over emphasized. They never questioned my goals, but instead provided regular words of wisdom as each step of my journey evolved. My late mother, Christy Sommers, was by far my biggest inspiration throughout this entire process. She understood the power and value of an education and her memory serves as a platform for all of my educational and life endeavors. 


\section{Table of Contents}

Table of Figures .................................................................................................................

List of Tables ................................................................................................................

Chapter 1: Literature Review.......................................................................................... 1

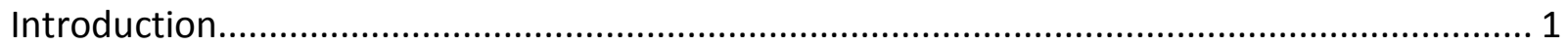

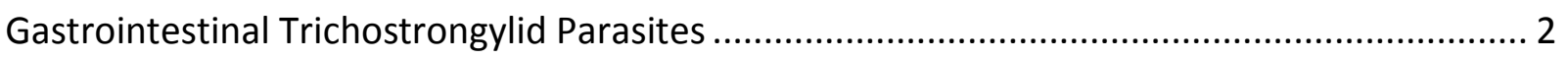

Life Cycle of Haemonchus contortus .................................................................................... 3

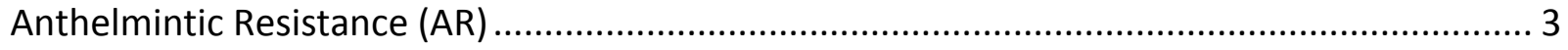

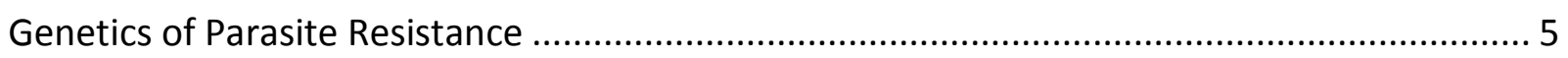

Breeding for Parasite Resistance ................................................................................ 5

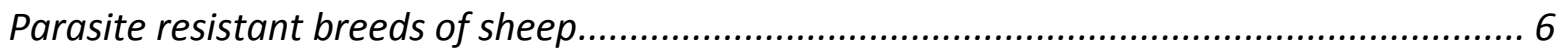

QTLs Associated with Parasite Resistance .................................................................... 7

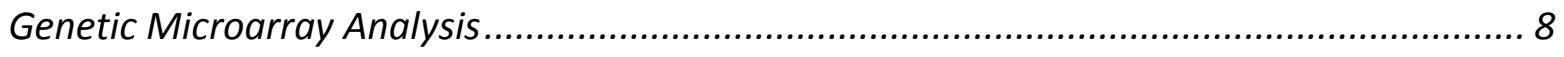

Immunology of Parasite Resistance ...................................................................................... 9

Immune Response of Parasite Resistant Sheep ............................................................... 9

Chapter 2: Immune related gene expression in parasite-resistant sheep during the first 10 days of a challenge Haemonchus contortus infection. ..................................................................... 13

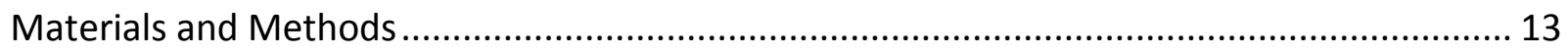

Sheep and experimental design- Experiment 1 ............................................................... 13

Sheep and experimental design- Experiment 2 .............................................................. 14

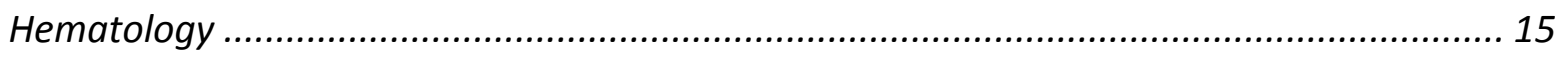

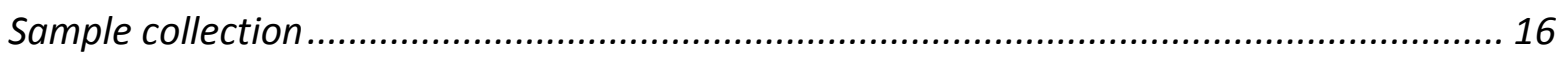

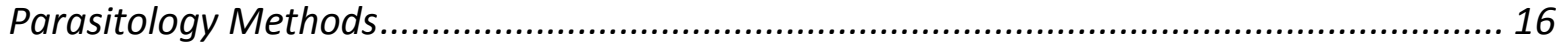

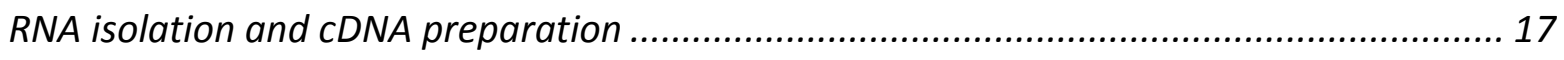

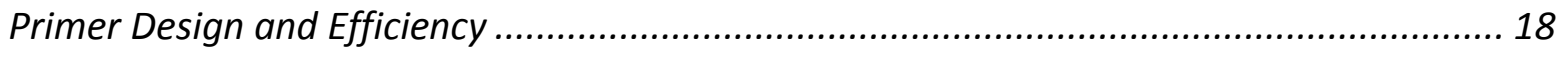

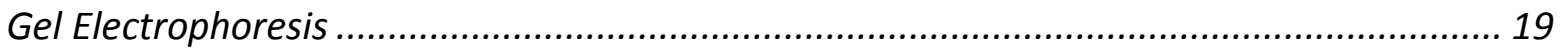

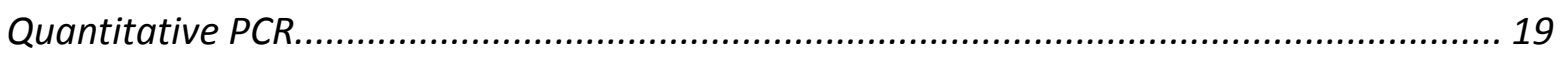




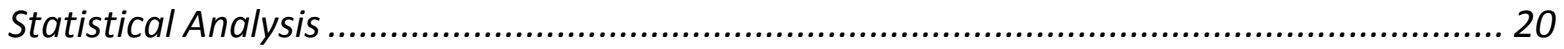

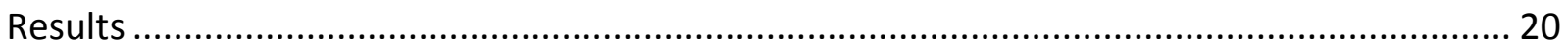

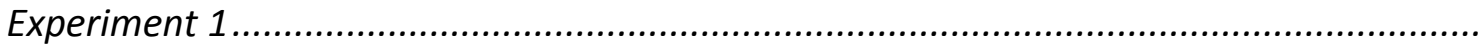

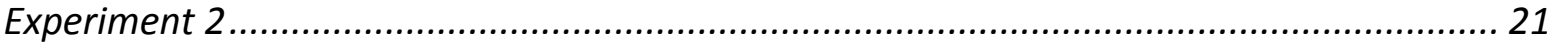

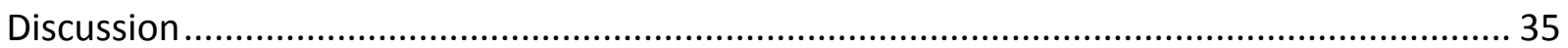

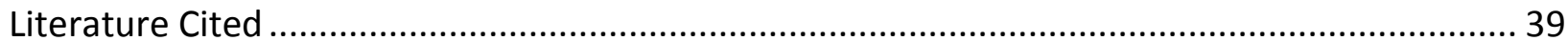




\section{Table of Figures}

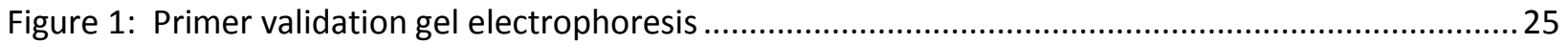

Figure 2: Gene expression in abomasal mucosa and lymph node 0, 3, 5, and 7 d.p.i.............................26

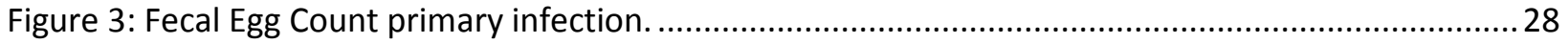

Figure 4: Packed Cell Volume (PCV) during 10 day challenge infection ..................................................29

Figure 5: White blood cell (WBC) count during 10 day challenge infection...........................................30

Figure 6: Circulating eosinophil counts during primary and 10 day challenge infection.......................... 31

Figure 7: Total worm burden 10 days post challenge infection ................................................................32

Figure 8: Abomasal lymph node development 10 days post challenge infection .................................... 33

Figure 9: qPCR analysis of mucosa IL4 expression 10 days post challenge infection ................................34 


\section{List of Tables}

Table 1: Biological categorization of candidate genes and their primer sequences ................................23

Table 2a: qPCR gene expression analysis of abomasal fold tissue experiment 1 ....................................27

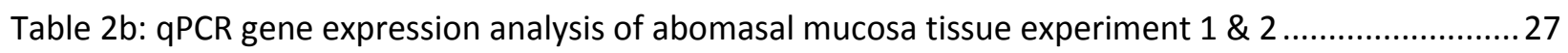




\section{Chapter 1: Literature Review Introduction}

Gastrointestinal parasite populations affecting small ruminants are increasingly less susceptible to anthelmintics drugs commonly used to treat infections and multidrug resistance is becoming the norm. This translates to billions of dollars of losses to commercial sheep producers worldwide (Roeber et al., 2013). Haemonchus contortus is of particular concern to producers because it feeds on the blood of its host. As new anthelmintics are becoming commercially available, it is ever more important to maintain drug efficacy by implementing alternative forms of parasite control. Rotational grazing, selectively treating animals, and breeding for resistance have shown some improvement. However, implementation of naturally parasite-resistant breeds of sheep shows the most potential for parasite control.

Every sheep breed has individuals that are more resistant than others, but comparison studies have identified entire breeds with greater parasite resistance. St. Croix hair sheep evolved on the St. Croix Island where climatic conditions are favorable for parasite development. Constant parasite exposure has resulted in a superior naturally acquired resistance to parasites like $H$. contortus. Genetic comparisons of the St. Croix and other more susceptible breeds have associated resistance with immune function. The ability of the St. Croix to resist $H$. contortus is due to a well-defined T- helper (Th2) type 2 supported by a fast innate immune cell response and a long lived humoral response (Gamble and Zajac, 1992; MacKinnon et al., 2009; Bowdridge et al., 2013). An underlying mechanism for resistance and an accurate characterization of early cellular immune response are still not well understood. Additionally, 
the focus for many studies has been towards the early larval infection ( $<7$ days post infection) or later when adults are present (<14 days post infection). No studies have been conducted to examine the later stages of the larval infection between days 7 and 14 .

Thus, the focus of the experiments conducted for this thesis was to identify differential gene expression during the first 10 days of a challenge $H$. contortus infection. The second experiment focuses exclusively on gene expression during day 10 post challenge infection. Identification of patterns in genes differentially expressed between parasite resistant and parasite susceptible animals before the presence of adult worms may reveal the mechanisms that define parasite resistance in sheep.

\section{Gastrointestinal Trichostrongylid Parasites}

Gastrointestinal nematode (GIN) infection is of great concern worldwide as it can negatively impact production, increase costs of prevention and treatment, and may result in animal death. In reality, infection is normal in sheep, however, infection intensity and clinical signs associated with disease can vary considerably (Roeber et al., 2013). Most infections result in minimal damage unless conditions change and alter the host's ability to govern the infection, leading to death depending on the nematode species present (Miller and Horohov, 2006). Of all the species of GIN commonly found in sheep, the family Trichostrongylidae are most abundant and cause greatest losses in production (Chilton et al., 2006). Common trichostongylid species include Heamonchus contortus, Teladorsagia circumcincta and Trichostrongylus colubriformis. (Donald and Waller, 1973). 


\section{Life Cycle of Haemonchus contortus}

Haemonchus contortus is a blood sucking GIN parasite that targets the mucosal lining of the abomasum. The simplistic life cycle begins when adult females lay eggs that are passed through the host's feces. First-stage (L1) larvae develop and hatch from the eggs, then further develop into free-living pre-parasitic second stage (L2) and an infective third stage (L3). This process under optimal environmental conditions takes roughly seven days. The cuticle maintained by L3 provides some protection from environmental conditions. Haemonchus contortus favors warm, moist climates with optimum conditions from May through September (Lauren et al., 2006). During winter months, L3 undergo hypobiosis and become metabolically inactive. Mature and active L3 reach life cycle completion by being ingested and undergoing two additional molts within the host to a reproductively active adult (Veglia, 1916).

As this parasite feeds on blood, a need to control infection level within a host is paramount as to avoid severe anemia. In young animals, adult $H$. contortus worms are capable of depleting one fifth of total circulating erythrocyte volume daily and adult sheep may lose up to one tenth of their erythrocyte volume in a day (Georgi and Whitlock, 1967). Besides anemia, other symptoms of haemonchosis include: weakness, lack of growth, poor body and wool conditions, and sub-maxillary edema or "bottlejaw." The most common treatment for haemonchosis involves utilization of commercially available anthelmintics.

\section{Anthelmintic Resistance (AR)}

Overuse of three major classes of anthelmintics has led to resistance in GIN populations (Blouin et al., 1995; Kaminsky et al., 2008). Reduced susceptibility to available anthelmintics is brought about in GIN by rapid rates of nucleotide sequence evolution and extremely large 
genetically diverse populations and short generation interval. Natural random mutations in unselected worms result in changes of receptor sites in which anthelmintics target, or create differences in enzymes, transport mechanisms, or anthelmintic metabolism (Anderson et al., 1998). Ultimately, development of anthelmintic resistance (AR) depends on parasite fitness by means of life cycle completion, egg production, pasture survival and immigration of resistant genes (Coles et al., 1992).

Traditional means of chemotherapeutic control relied heavily on three main classes of anthelmintics- benzimidazoles, imidazothiazoles, and macrocyclic lactones. Commercial limitations of only three drug classes have resulted in overuse, waning drug efficacy, and prevalence of multidrug resistance. These factors motivated development of two new anthelmintic classes in recent years: amino-acetonitrile derivatives (AAD) and spiroindoles (Kaminsky 2008, Epe 2013). However, there is a potential for development of AR to these new classes. Unless sustainable control practices are implemented (Kaplan, 2004). One method in which to slow progression of $A R$ is by maintaining a population of nematodes susceptible to anthelmintics, known as refugia (van Wyk and Bath, 2002; Coles, 2005; Sissay et al., 2006; Laurenson et al., 2013). Maintaining susceptible genetics in a worm population serves to dilute the impact of AR worms, thus extending the efficacy of anthelmintics. The Faffa Malan's Chart (FAMACHA) system, developed in South Africa, allows for selective anthelminthic treatment by estimating parasite burden through the level of anemia seen in the conjunctiva. Depending on how the animal scores will determine whether or not they receive treatment (van Wyk and Bath, 2002; Kaplan et al., 2004; Riley and Van Wyk, 2009). 
Other alternative strategies include adequate host nutrition to reduce effects of parasitism. Protein supplementation can increase the rate of immune development and resilience against gastrointestinal nematodes (Coop and Kyriazakis, 1999; Abbott et al., 2004). The implementation of rotational grazing strategies can limit exposure and reduce fecal egg counts (Colvin et al., 2012) and efforts towards vaccine development, although not commercially available, are also avenues of consideration in parasite control (Geary and Thompson, 2001; Knox et al., 2001). Unfortunately, none of the non-chemotherapeutic methods for parasite control is sufficiently effective without some anthelmintic involvement (Coles et al., 2006; Jabbar et al., 2006).

\section{Genetics of Parasite Resistance}

\section{Breeding for Parasite Resistance}

The ability to resist infections is a key component of parasite control and management. Resistance to GIN infections requires the initiation and maintenance of a host response that prevents, reduces, or removes parasitic infection (Gamble and Zajac, 1992; Hooda et al., 1999; Bowdridge et al., 2013). Resistant animals, persistently exposed to new helminth infection are not completely free of adult worms, but consistently have lower parasitic load than susceptible animals, as measured by fewer eggs in their feces (Gill, 1991).

There are several ways to assess resistance to GIN. The most accurate way is to quantify total parasite load of the host, but this can only be done upon necropsy (Pfeffer et al., 1996; Hooda et al., 1999). The most common method is fecal egg count (FEC), which has limitations as egg count in feces is not necessarily correlated with the host's parasite load (Stear and Murray, 
1994). Selecting for low FEC results in variable heritability $\left(h^{2}\right)$, ranging from 0.22 and 0.63 , depending on factors such as time of year, animal's age, and artificial vs natural infection. (Windon, 1996; Miller and Horohov, 2006; Pickering et al., 2012). As a result of moderate heritability, genetic improvement of resistance takes time. For example, approximately 10 years of intense selection of Australian Merino sheep resulted in up to $50 \%$ reduction in FEC as compared to an unselected flock (Woolaston, et al., 1996). The time it takes for improvement via artificial selection has motivated interest in breeds of sheep that have been naturally selected for superior parasite resistance.

\section{Parasite resistant breeds of sheep}

Use of PR breeds of sheep has been proposed as a method of managing the impact of GIN on grazing sheep. The tradeoff being a reduction in many economically important production traits (Gray, 1997). Differences in breed susceptibility to GIN infection was first reported in 1937, where higher resistance to Teladorsagia circumcincta, based on lower FEC,

was seen in Romney Marsh lambs compared to Rambouillet, Shropshire, Southdown, and Hampshire lambs (Stewart, Miller et al. 1937). However, Romney Marsh lambs have less PR as compared to Red Maasi hair sheep (Mugambi et al., 1997). More recent comparison studies conducted have shown similar results in that some hair sheep breeds, such as the Red Maasi, Santa Ines, Katahdin, Barbados Blackbelly, and St. Croix, consistently present with lower numbers of adult worms and shed fewer parasite eggs than susceptible breeds such as Suffolk, Dorest, and Rambouillet (Amarante et al., 1999; Notter et al., 2003; Burke and Miller, 2004; Vanimisetti et al., 2004). 
Resistance of some breeds can be explained by their origin. Breeds resistant to GIN infection were typically developed in areas where climatic conditions allow for a highly parasitized environment, resulting in natural selection for GIN resistance. Having evolved in a tropical environment, hair sheep breeds, including Barbados Blackbelly and St. Croix have notably higher natural resistance to GIN with constantly higher blood packed cell volume and low FEC (Yazwinski et al., 1979; Courtney et al., 1985). With the exception of the Dorper breed (Burke and Miller, 2004), hair sheep seem to have increased resistance to internal parasitism compared with most wool breeds (Zajac et al., 1990; Mugambi et al., 1997; Wildeus, 1997).

\section{QTLs Associated with Parasite Resistance}

Ideally, genetic markers associated with GIN resistance should be used to more accurately select sheep within breed, but polygenetic traits present certain challenges when determining possible causative genes. Resistance has been associated with quantitative trait loci (QTL) mapped, most notably, to chromosomes 3 and 20. Chromosome 3 contains the IFNy locus (Dominik, 2005; Marshall et al., 2009) and chromosome 20 is the location of ovine MHC (OMHC1-188) alleles (Outteridge et al., 1996; Castillo et al., 2011). The presence of these QTLs in animals was associated with reduced FEC in some studies (Schwaiger et al., 1995; Castillo et al., 2011), but not in others (Marshall et al., 2009). Although inconstant in their association with FEC reduction, these QTLs are consistently associated with genomic regions involved in immune responses. 


\section{Genetic Microarray Analysis}

Development of microarray technology for ruminant species allowed for large scale evaluation of differentially expressed genes, during sheep parasite infections. A 10,204 bovine cDNA microarray identified over 100 differentially expressed genes during natural GIN infection. Further classification of these genes revealed that two processes, development of an acquired immune response and smooth muscle function, are important in governing genetic resistance to GIN (Diaz-Tascon et al., 2005). MacKinnon et al. (Mackinnon et al., 2009) found that resistant and susceptible sheep exhibited differential gene expression that was associated with a nonspecific response to $H$. contortus. At 3 days post infection (PI) with $H$. contortus, resistant sheep had reduced expression of genes associated with blood coagulation and higher expression of genes involved in the inhibition of coagulants, tissue repair and restructuring, blood vessel formation, and cell migration in the abomasum and abomasal lymph node. At 27 days PI, resistant sheep had higher expression of genes associated with gastrointestinal motility, inflammation, cell differentiation and proliferation. Most recently, transcriptome analysis of abomasal lymph nodes of resistant and susceptible sheep were evaluated. The ovine-specific array identified 44 differentially expressed genes with associated functions to humoral immunity, protein synthesis, inflammation, and immune cell trafficking. Within these networks, up-regulation of interleukin (IL) 4, IL5, IL13R $\alpha 2$, IL13 and genes linked to inflammation regulation are hallmark to the resistance phenotype (Gossner et al., 2013).

The recurring theme in these genetic analysis studies is that genes involved in immune responses and processes are being up-regulated during GIN infection and defining the parasite 
resistant phenotype. However, a better understanding of the immune response in PR sheep is still needed in order to characterize the underlying immune mechanism.

\section{Immunology of Parasite Resistance}

\section{Immune Response of Parasite Resistant Sheep}

Immune mechanisms by which sheep have or acquire resistance to $H$. contortus are not completely understood. However, it has been documented that both innate and adaptive immune responses protect the host from $\mathrm{H}$. contortus infection (Saddiqi et al., 2011; Shakya et al., 2011). Clearance of the parasite in sheep requires a carefully choreographed series of events, including the activation of nonspecific defense mechanisms, recognition of parasitic antigens, and the initiation of an appropriate acquired response (Meeusen et al., 2005).

Once $H$. contortus reaches the abomasum, it comes into direct contact with the mucosal surface which acts as an initial chemical barrier to invading pathogens. As early as four days post ingestion of L3 larvae, H. contortus can start feeding on blood (Albers and Le Jambre, 1983) causing damage to abomasal tissue. The host will respond to the damage in a way that is typical of any wound including: bleeding, coagulation, inflammation, and regeneration and remodeling of affected tissues. Expression of pro-inflammatory cytokines, tumor necrosis factor- $\alpha$ (TNF $\alpha$ ) and IL1 $\beta$, are typical and required to trigger innate responses associated with the complement cascade. Cytokine production by damaged cells and initiation of complement will recruit and activate innate immune cells, mast cells, neutrophils, eosinophils, dendritic cells, and macrophages, to the site of infection (Velnar et al., 2009). This influx of immune cells can also aide in immediate expulsion of the parasite. Immediate expulsion occurs when larvae are 
confronted by tissue mast cells and globule leucocytes resulting in hypermotility, increased gastric secretion, and increased mucus production; which are damaging to the fecundity and motility of the worm (Hohenhaus and Outteridge, 1995; Miller, 1996; Balic et al., 2002).

The most important aspect of innate immunity is foreign antigen recognition and presentation. Antigen presentation is accomplished by dendritic cells (DCs) and that constantly test their environment for antigen. Infections of $H$. contortus result in antigens specific to the various life cycle stages. Some antigens specific to $L 3$ and $L 4$ are not expressed during the adult stage, essentially making stage an immunologically unique organism that antigen presenting cells (APC) have to recognize (Meeusen et al., 2005). However, once foreign antigen is recognized, APCs will reduce antigen to polypeptide, migrate to lymph tissue, and present it to developing lymphocytes. Parasite antigen presentation will then induce lymph node hypertrophy as the quantity of $\mathrm{CD}^{+}{ }^{+} \mathrm{T}$-cells increase and are released into the blood and homed to the site of infection (Gill, 1994; Jacobs et al., 1995). Development of CD4 ${ }^{+}$T-cells is imperative to immunity towards $H$. contortus infection. Neutralization studies have shown that sheep without $\mathrm{CD}^{+} \mathrm{T}$-cells had increased parasite burden and suppression of mucosa mast cells, eosinophil infiltration, and development of humoral memory response (Gill et al., 1993; Peña et al., 2006). Activation of $\mathrm{CD}^{+}{ }^{+} \mathrm{T}$-cells is also needed for development of antigen specific B cells (Murphy, 2012) capable of producing immunoglobulins (Ig) G, A and E (Pernthaner et al., 2005; Lacroux et al., 2006; Shakya et al., 2011).

Depending on the activation stimuli and cytokine environment, $\mathrm{CD4}{ }^{+} \mathrm{T}$-cells differentiate into multiple phenotypes whereby two are most common. Type 1 T-lymphocytes (Th1), 
characterized by the production of IFNY and IL-2, constitute the cellular response and protect against intracellular parasites. Type 2 lymphocytes (Th2) are part of the humoral response and are characterized by production of IL-4, IL-5, IL-13 and IL-25 (Zhu et al., 2006). Adaptive immunity against parasite in resistant sheep requires a T-helper 2 (Th2) response and is essential for the development of resistance to GINs in sheep (Robinson et al., 2010). In resistant sheep, Th2 response is associated with elevated levels of parasite-specific IgA, IgE and IgG antibodies, eosinophilia, mast cell infiltration, and goblet cell hyperplasia (Gill, 1994; Pernthaner et al., 1995; Meeusen et al., 2005; Bowdridge et al., 2013).

Even though acquired immunity to $H$. contortus is driven by a sub-population of T-helper cells and mature antibody-producing B cells, innate cells such as mast cells, eosinophils, neutrophils and macrophage populations are required to maintain the cytokine environment needed for Th2 immunity and worm expulsion (Meeusen et al., 2005; Robinson et al., 2010). Infiltrating mast cells, eosinophils, and neutrophils release their cytotoxic payload during degranulation, which consist of antimicrobial peptides, chemokines, histamines, and proteases. Many of these molecules also act as chemoattractants, such as MCP-1, which recruits monocytes and reduce helminth fecundity (Saluja et al., 2012). Neutrophils are typically the first cells to respond to pathogens in the body via release of the chemokines IL- 8 and CXCL1 (Kolaczkowska and Kubes, 2013). Tissue and blood eosinophils also increase via IL-5 production and their subsequent degranulation has been shown to have cytotoxic effects towards $H$. contortus larvae (Rainbird et al., 1998). Influx of neutrophils and eosinophils early on during $H$. contortus infection could indicate importance in larval infection and may differentiate parasite resistant from parasite susceptible sheep (Shakya et al., 2011). 
Monocytes recruited to the site of infection typically differentiate further into macrophages. However, the resulting macrophage phenotype is dependent on the cytokine environment. In the presence of the Th1 cytokine interferon- $\gamma$ (IFN $\gamma)$, macrophages shift toward a classically activated (M1) phenotype. These cells engulf and destroy microorganisms through pathways that are dependent on inducible nitric oxide synthesis (iNOS). However, in the presence of Th2 cytokines, the macrophage phenotype shifts towards an alternatively activated macrophage (M2). The M2 are distinguishable by their expression of arginase-1 (ARG1), IL-4 receptor- $\alpha$ (IL-4R $\alpha$ ), and mannose receptor (MRC1) (Hesse et al., 2001; Anthony et al., 2006). Alternatively activated macrophages appear to have at least three principal functions: regulation of the immune response, wound healing and resistance to parasite invasion. Their contribution to wound repair may be by expression of RELM $\alpha$ and $\beta$, prolines, transforming growth factor- $\beta$ (TGF $\beta$ ), and matrix metalloproteinase (MMPs) (Gratchev et al., 2001; Hesse et al., 2001).

As outlined, many immunological processes are involved GIN infections including inflammation, tissue remodeling/ wound repair, cell signaling, immune cell recruitment, and differentiation of particular cell types. Many genes and combinations of genes will be enlisted to see these processes through. Genes that code for cytokines are of particular interest because they are the main mode for cell communication and are produced by broad range of immune and somatic cells. However, in the context of $H$. contortus infections, some genes are associated with primarily one cell type. As discussed previously, this is the case for macrophages and naïve T-cells that can further differentiate with each sub-population upregulating specific sets of genes. No studies take a comprehensive approach to gene 
expression. They primarily focus on one aspect of the host response. Additionally, these studies do not offer a collective view of gene expression during each stage of parasite development within the host. There has been focus on the early larval infection and the adult stages, but there is a gap in the literature that is consistent with late larval infection.

\section{Chapter 2: Immune related gene expression in parasite-resistant sheep during the first $\mathbf{1 0}$ days of a challenge Haemonchus contortus infection.}

\section{Materials and Methods}

Sheep and experimental design- Experiment 1

In 2009, at Virginia Tech, twenty-four St. Croix hair sheep and twenty-four composite wool lambs were used in an experiment conducted by Dr. Scott Bowdridge. Parasite susceptible composite wool lambs were composed of 50\% Dorset, 25\% Rambouillet and 25\% Finnsheep. To ensure prior exposure to $H$. contortus, all lambs grazed naturally infected pastures for 30 days post weaning and received a trickle infection of $2,000 \mathrm{H}$. contortus $L_{3}$ larvae weekly for 4 weeks 
prior to the start of the experiment. Lambs were then treated with levamisole $(8 \mathrm{mg} / \mathrm{kg})$ and rested on drylot for 3 weeks.

Six lambs from each breed were randomLy assigned to 4 treatment groups/days, representative of time of sacrifice post challenge infection. Day 0 lambs received no infection, while Days 3, 5, and 7 received 10,000 H.contortus $L_{3}$ at the start of the experiment. Lambs were humanely euthanized using captive bolt-gun stunning followed by exsanguination. All samples were collected at the Virginia Tech Meats Laboratory. Methods of infection, sample collection and euthanasia were in compliance with Virginia Tech Institutional Animal Care and Use Committee.

\section{Sheep and experimental design- Experiment 2}

Twelve St. Croix hair lambs and twelve crossbred Suffolk wool lambs were selected for this experiment and randomLy assigned to two groups (Naïve and Challenge). All lambs were raised on an elevated floor at West Virginia University Animal Science farm. The raised floor ensured that the animals remained naïve of GIN parasites prior to primary infection. Challenge group animals received a primary infection of $10,000 \mathrm{H}$. contortus $L_{3}$ on July 10,2013 . Primary infection persisted for 5 weeks and was monitored with weekly FEC and PCV analysis. Animals were then dewormed with Levasole $(1 \mathrm{~mL} / 10 \mathrm{lbs}$ body weight). Fecal egg counts were monitored for the following nine weeks while animals rested to ensure that fecal egg counts remained at zero. During the rest period, prior to the start of the challenge infection, one of the St. Croix hair animals in the Challenge group died due to causes unrelated to experiment. This resulted in 11 St. Croix hair sheep and 12 crossbred Suffolk wool sheep for the remainder of the 
experiment. On day zero, Challenge animals received a dose of $10,000 \mathrm{H}$. contortus $L_{3}$ larvae; naïve animals remained uninfected. Ten days post challenge infection, all lambs were humanely euthanized using captive bolt-gun stunning followed by exsanguination. All samples were collected at the Virginia Tech Meats Laboratory. Methods of infection, sample collection and euthanasia were in compliance with West Virginia University Animal Care and Use Committee.

\section{Hematology}

Prior to sacrifice, blood samples were collected every two days via jugular venipuncture in EDTA-treated $4 \mathrm{~mL}$ vacutainer tubes (Tyco, Mansfield, MA) for packed cell volume, total white blood cell counts, and eosinophil staining.

\section{Packed cell volume}

Heparin treated microhematocrit tubes (StatSpin, Westwood, MA) were filled with whole blood. Tubes were positioned into a microcetrifuge (StatSpin, Westwood, MA) and centrifuged for 3 minutes. Digital hematocrit reading determined red blood cell percentage (StatSpin, Westwood, MA).

\section{Total white blood cell}

A mixture of $10 \mathrm{~mL}$ Isoton II diluent (Beckman Coulter, Pasadena, CA) and $20 \mu \mathrm{L}$ whole blood was added coulter counter sample cups for a 1:500 dilution. Three drops of Zap-oglobin (Beckman Coulter, Pasadena, CA) lysing agent was added and gently swirled. Total white blood cell was determined with a Coulter Counter (Beckman Coulter, Pasadena, CA). 


\section{Eosinophil staining and counting}

Eosinophils were enumerated by combining $25 \mu \mathrm{L}$ whole blood with $375 \mu \mathrm{L}$ Phyloxin B solution in $1.5 \mathrm{~mL}$ conical microtubes. The solution was mixed well and incubated at room temperature for 10 minutes. Each side of a hemacytometer was loaded with $12 \mu \mathrm{L}$ of the solution and stained eosinophils were counted (Costello, 1970)

\section{Sample collection}

Upon evisceration at the Virginia Tech Meats Laboratory, the abomasum and superficial fat along the lesser curvature was isolated and removed. All palpable lymph nodes were extracted from the fat. Lymph nodes were counted and weighed and the largest lymph node was cut longitudinally and placed in RNAlater (Invitrogen, Burlington, ONT Canada). The abomasum was cut along the greater curvature and contents were washed gently with water. Mucosa samples from the fundic region were collected by scrapping the lining of the abomasum with a glass slide and added to RNAlater. Full thickness fundic tissue samples, including an abomasal fold, were dissected out and placed in RNAlater.

\section{Parasitology Methods}

Feces of donor sheep, maintained at the WVU Animal Science farm, were collected and cultured at $30^{\circ} \mathrm{C}$ for 7 to 8 days in a mixture of activated charcoal and sterile peat moss. The Baermann technique (Zajac and Conboy, 2006) was then used to collect Haemonchus contortus $L_{3}$ larvae. Fecal egg counts were determined using the modified McMaster's technique (Whitlock, 1948). Each egg counted represented 50 eggs per gram of feces. Total worm count, for part II of the experiment, was determined by collecting the gut contents from the abomasum of each animal. A $10 \%$ aliquot of the abomasum content was preserved in buffered 
formalin and half of the abomasum was soaked in water overnight. The abomasum was removed and buffered formalin was mixed 1:1 with the soak fluid. The $10 \%$ aliquot and soak fluid were then run though strainers to remove undesired particulate matter. The strainers were rinsed gently and contents collected. All parasites present were then counted by the use of a gridded Petri dish and stereoscopic microscope.

\section{RNA isolation and CDNA preparation}

Abomasal and lymph node samples were preserved in RNAlater (Invitrogen, Burlington, ONT Canada). Total RNA was isolated from abomasal mucosa, abomasal lymph node, and abomasal fold tissues. A $100 \mathrm{mg}$ tissue sample was homogenized in $1.5 \mathrm{~mL}$ RNA-bee (Tel-Test, Friendswood, TX) after which $150 \mu \mathrm{L}$ chloroform/isoamyl (Sigma-Aldrich, St. Louis, MO) was added, vortexed for 15 seconds then incubated on ice for 5 minutes. Sample was centrifuged for 15 minutes at $14,000 \times g$ at $4^{\circ} \mathrm{C}$. Aqueous layer was retained and placed in a new tube where RNA was precipitated by addition of equal volume isopropanol and incubated on ice for 15 minutes. Samples were centrifuged for 15 minutes at $14,000 \times g$ at $4^{\circ} \mathrm{C}$ and washed twice with $1 \mathrm{~mL} 75 \%$ ethanol, dried, and dissolved in $20-50 \mu$ IEPC-treated water. Quality of RNA was determined by NanoDrop ${ }^{\mathrm{TM}} 1000$ Spectrophotometer (Thermo Scientific, Wilmington, DE) for an $\mathrm{OD}_{260} / \mathrm{OD}_{280}$ ratio of $>1.8$. RNA from each sample was diluted to $1.8 \mu \mathrm{g} / 13 \mu \mathrm{L}$ of DEPC-treated water. The following Master Mix components were added: $2.5 \mu \mathrm{L}$ of 2.5nM dNTP (GE Illustra, Buckinghamshire, UK), 5.0 $\mu \mathrm{L}$ 5X reverse transcriptase buffer (Life Technologies, Burlington, ONT

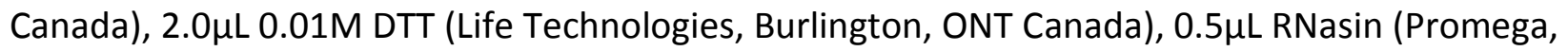
Madison, WI), and $2.0 \mu \mathrm{L}$ random hexamer primers (Life Technologies, Burlington, ONT). Samples were denatured at $70^{\circ} \mathrm{C}$ for 5 minutes then chilled at $4^{\circ} \mathrm{C}$ for 5 minutes. Then $1 \mu \mathrm{L}$ 
SuperScript ${ }^{\mathrm{TM}}$ II reverse transcriptase (Life Technologies, Burlington, ONT Canada) was added to each sample finishing the RT reaction conditions of $37^{\circ} \mathrm{C}$ for 60 minutes, $90^{\circ} \mathrm{C}$ for 5 minutes, and then $4^{\circ} \mathrm{C}$ for 5 minutes. Final cDNA preparations were stored at $-20^{\circ} \mathrm{C}$.

\section{Primer Design and Efficiency}

Primer design was based on mRNA sequences found in the NCBI database. For each candidate gene, primers were selected using Primer3 software (Rozen S and Skaletsky H., 2000). The following changes were applied to the default program parameters: product range 80-120 bp; primer $T_{\mathrm{m}} 59-61{ }^{\circ} \mathrm{C}$; primer GC\% 40-60; max self-complementarity 3; max 3' selfcomplementarity 1 ; max poly-x 3 . Forward and reverse primer sequences were purchased from Integrated DNA Technologies; genes, associated GenBank accession numbers and sequence of primers used in qPCR assays are shown in Table 1. All primers were original except interleukin 5 (Robinson N, 2011). The efficiency for each primer was derived from the slope of the regression line fitted to a subset of baseline-corrected data points in the log-linear phase using LinRegPCR (Ramakers C, 2003). Efficiency for each primer was always higher than $(1+E)=1.96$.

Melting curve analysis resulted in only one well defined peak per reaction indicating that only one PCR product was amplified. Melting temperature $(\mathrm{Tm})$ of these products were consistent with theoretical Tm of the expected PCR products. Only one band was visualized after agarose gel electrophoresis of all amplified products (Figure 1). 


\section{Gel Electrophoresis}

A 3\% agarose gel was prepared to check qPCR primer products for expected amplicon length (Figure 1). Five times concentrated TBE buffer solution was composed of 54g Tris base, 27.5g boric acid, and 3.72g EDTA (Fisher Scientific, Fair Lawn, NJ). Buffer solution was diluted to $1 x$ concentration to be used for both gel preparation and running buffer. A mixture of $50 \mathrm{~mL}$ TBE and 1.5g Agarose (Fisher Scienctific, Fair Lawn, NJ) was microwaved on medium heat for 2 minutes, stirred, and reheated on high for 1-2 minutes or until boil. Mixer was swirled with 5 ul RGB stain (Phenix Research Products, Candler, NC), cooled to $60^{\circ} \mathrm{C}$, and poured into casting tray. Quantitative PCR products for each primer and ladder were mixed with a $6 x$ loading dye. Five microliters of qPCR products and ladder were then loaded into a $5 \mathrm{~mL}$ agarose gel. Electrophoresis was allowed to run for 1.5 hours at $95 \mathrm{~V}$.

\section{Quantitative PCR}

All qPCR reactions for each sample were done in duplicate with a Bio-Rad CFX96 system. Reaction conditions were: $50^{\circ} \mathrm{C}$ for 10 minutes and an initial denaturation at $95^{\circ} \mathrm{C}$ for 5 minutes followed by 40 cycles of denaturation at $95^{\circ} \mathrm{C}$ for 10 seconds and extension for 30 seconds at $60^{\circ} \mathrm{C}$. A ramp temperature between $65^{\circ} \mathrm{C} \mathrm{MT}$ and $95^{\circ} \mathrm{C}$ was used to obtain the melting curves. PCR amplifications were carried out in a total volume of $20 \mu \mathrm{l}$, containing $10 \mu \mathrm{L}$ SYBR Select Master Mix (Life Technologies, Burlington, ONT Canada), 1.2 $\mu \mathrm{L}$ of each forward and reverse primers, $2 \mu \mathrm{L} 10 \mathrm{ng} / \mu \mathrm{L}$ diluted cDNA template, and 5.6 $\mu \mathrm{L}$ DECP-treated water. The relative fold change in gene expression of candidate genes was done using the $2^{-\Delta \Delta C t}$ method (Livak and Schmittgen, 2001). The obtained Ct values are used to calculate $\Delta C t$ values of genes of interest [Ct (test) - Ct (reference)]. The reference gene used for normalization was GADPH. The $\Delta \Delta \mathrm{Ct}$ 
values were obtained in reference to the Day 0 control animals. Graphical representation for each gene was based on fold change.

\section{Statistical Analysis}

All data from experiment was analyzed using SigmaPlot (Systat Software, Inc., San Jose, CA). Data from qPCR is reported as fold change. However, statistical analysis for qPCR data was done with a Two Way ANOVA on the $\log (\Delta \mathrm{Ct}, 2)$ values followed by a Dunnett's test to compare each treatment back to control for each sheep breed. Differences with $P \leq 0.05$ were considered statically significant. Fecal egg counts were log transformed as $\log _{10}(\mathrm{FEC}+25)$ because they were not normally distributed.

\section{Results}

\section{Experiment 1}

\section{Gene Expression}

During days 0-7 post challenge $H$. contortus infection, only one gene evaluated showed any significant differences between breeds within the lymph node. Wool animals had greater overall expression of transcription factor Forkhead box P3 (FOXp3) $(P<0.05)$ as compared to hair animals (Figure 2 a).

Abomasal fold tissues resulted in higher overall expression in monocyte chemotactic protein-1 (MCP1) $(P<0.01)$, matrix metalloproteinase- $13(\mathrm{MMP} 13)(P<0.001)$, plateletderived growth factor (PDGF) $(P<0.05)$, tumor necrosis factor-alpha (TNF $\alpha)(P<0.01)$ in wool animals (Table 2a). Hair animals showed no differentially expressed genes within the fold. 
Mucosa samples from days 0-7 post challenge infection resulted in a roughly two fold increase in expression of gamma-delta T-cell maker (WC.1) $(P<0.05)$, vascular endothelial growth factor (VEGF) $(P<0.01)$, interleukin-3 (IL3) $(P<0.01)$, interleukin-6 (IL6) $(P<0.01)$, tumor necrosis factor-alpha (TNF $\alpha)(P<0.01)$, and complement component 3 (C3) $(P<0.01)$ in wool animals. Additionally, there was down regulation of annexin-3 (ANXA3) $(P<0.01)$, chemokine receptor-3 (CXCR3) $(P<0.01)$, and peroxisome proliferator-activated receptor gamma $(\operatorname{PPAR} \gamma)(P<0.05)$ in hair animals. However, hair animals expressed more arginase-1 (ARG1) $(P<0.05)$, galectin-14 (GAL14) $(P<0.05)$ (Table 2b), chemokine ligand-1 (CXCL1) $(P<$ 0.001) (Figure 2b), significantly greater expression of MCP-1 $(P<0.05) 7$ dpi (Figure $2 c)$ then wool animals. Most significantly, there was no detection of, Th2 cytokines, interleukin (IL)-4 or IL-5 in wool animals (Figures 2d, e). Additionally, IL-4 expression in hair animals was not detectable until day 3 post infection (Figure $2 d$ ).

\section{Experiment 2}

\section{Fecal egg counts}

During the primary infection, wool animals generated a FEC over twice that of the hair animals $(P<0.01)$. Wool animals saw a consistent rise in $F E C$ from 0 eggs/g on day 14 to a peak (11,466 eggs/g) on day 35 (Figure 3). Hair FEC saw a rise to day 21 where it plateaued until day 28 (3,117 eggs/g). Hair FEC then saw a reduction (1,908 eggs/g) by day 35 . All naïve animals remained at zero (eggs/g) throughout the duration of the primary infection. All animals received a Levasole ( $1 \mathrm{~mL} / 10$ lbs body weight) treatment on day 35 and rested for 9 weeks. Fecal samples were taken on day 0 and 7 during the 10 day challenge infection. All animals had a FEC of zero for both collections. 


\section{Hematology}

During the ten day infection, experiment 2, no difference was observed in packed cell volume between the animal types or the treatments (Figure $4 a, b)$. The same can be said for total circulating white blood cells (Figure 5a, b).

Circulating eosinophils form the primary infection resulted in no significant difference between animal types or treatments (Figure 6a). As expected infected animals, during the challenge infection, presented with eosinophilia $(P<0.05)$ as compared to naïve animals. However, animal type had no effect on the number of circulating eosinophils (Figure 6b).

\section{Total worm counts}

Wool animals supported an average worm burden in the abomasum ( $n=530$ ) as compared to hair animals $(\mathrm{n}=16)(P<0.05)$ (Figure 7). No adult worms were observed during enumeration and, as expected, no parasite burden was seen in naïve animals.

\section{Lymph node}

Significant lymph node proliferation was seen in challenge hair animals with roughly twice as many palpable lymph nodes then naïve animals or challenge wool $(P<0.05)$ (Figure 8a). There was no difference in lymph node weights between animal types. However, challenge animal lymph node weights were notably higher than naïve controls for each animal type $(P<$ 0.05) (Figure 8b).

\section{Gene Expression: Experiment 2}

At ten days post challenge infection there were no difference in expression of transcription factors: GATA3, FOXp3, and T-bet in lymph node tissues of either hair or wool 
breeds $(P>0.05)$. Mucosa samples on day 10 resulted in greater overall expression of interleukin 4 receptor- $\alpha($ IL4R $\alpha)(P<0.05)$ and matrix metalloproteinase-13 (MMP13) $(P<0.05)$ in wool animals (Table 2b). Mucosa samples also presented with down regulation of annexin-3 (ANXA3) $(P<0.01)$, arginase-1 (ARG1) $(P<0.05)$, and galectin-14 (GAL14) $(P<0.05)$ in hair animals as compared to wool (Table $2 \mathrm{~b}$ ). Interleukin-4 expression was not detectable in naïve and challenge hair animals or in naïve wool animals (Figure 9a). In order to have some graphical representation of the expression seen in challenge wool animals $10 \mathrm{dpi}$, a ratio of IL4 expression to GAPDH expression is presented (Figure 9a).

Table 1: Biological categorization of candidate genes and their primer sequences

Genes associated with helminth infections of murine, ovine and bovine models were selected. Primers developed using Primer3 software were based on published NCBI sequences and validated by melt curve and gel electrophoresis. 


\begin{tabular}{|c|c|c|c|c|c|c|}
\hline Gene Name & Abbr. & Forward Primer $5^{\prime}-3^{\prime}$ & Reverse Primer $5^{\prime}-3^{\prime}$ & Amplicon (bp) & Accession Number & $\mathrm{TM}$ \\
\hline \multicolumn{7}{|c|}{ Wound Healing / Tissue Remodeling } \\
\hline Annexin 3 & ANXA 3 & ACAGAAACATCAGCCAGAAGG & TCCTCGCA CAACGAACTA TG & 99 & XM_004009934.1 & 79 \\
\hline Arginase 1 & ARG1 & GTGAAGGAAGTGGAAAAGTAAGTGA & TGTAAGTTGGAGGAAAGGGAAA & 82 & $\mathrm{BC} 105497$ & 75 \\
\hline Cationic amino acid transporter 2 & САT 2 & AAGGAAA TGTGGCAAACTGG & CCCA TAGA CGCTTGTTCCA T & 101 & XM_004021849.1 & 77 \\
\hline Chitinase 3-like 1 & CHI3L1 & CAGATTCCGTGACCAGCA & CGTGCCTTGTTTTGACACTC & 90 & BT021835 & 83 \\
\hline Cyclooxygenase 2 & $\operatorname{cox} 2$ & CTACCCGCCTCATA TTCCTG & CCAAATGGTGGCATACATCA & 94 & U68486 & 82 \\
\hline Galectin 14 & GAL 14 & CGGAGGA GAAGAAGATGCAG & CCTTGAACGAGGAGCTGTCT & 84 & NM_001009251.1 & 78.5 \\
\hline Nitrice Oxide Synthase & iNOS & AGAAGAGGCTGAGA GGCAGA & GTGGGGCTGTTGGTGAACT & 81 & AF2239421 & 81.5 \\
\hline Matrix Metalloproteinase 3 & MMP 3 & GGTTGGAGGTGACA GGAAAG & CAGGAAAGGTGCTGAAGGAA & 99 & XM_004015970.1 & 82 \\
\hline Matrix Metalloproteinase 9 & MMP9 & CACCTACTCCGCCTGTACCT & TAGAGCTTGTCCTGGTCGTAGTT & 87 & FJ185130.1 & 80 \\
\hline Matrix Metalloproteinase 13 & MMP 13 & TATGCTTCCTGACGATGACG & GGCGTTTCGGATGTTTAGA & 87 & GQ221063.1 & 79 \\
\hline Plarelet-derived Growth Factor & PDGF & GA CCACTCCA TCCGTTCCT & TCCAATTCAGCTCCGTCTTC & 80 & NM 001009471.1 & 80 \\
\hline Peroxisome proliferator-activated receptory & PPARY & CTTGACGGGAAAGACGACA & GCTGA TGTGCTTGAACTTGATT & 97 & NM_001100921.1 & 75.5 \\
\hline Vascular endothelial growth factor & VEGF & CGAAAGTCTGGAGTGTGTGC & TATGTGCTGGCTTTGGTGAG & 85 & AF071015.1 & 79 \\
\hline Von Willebrand factor & VWF & AAGTGTGTCGGGAGCAGTGT & AGGGTATGGCTTTCAGCA & 119 & XM_004007587.1 & 86 \\
\hline \multicolumn{7}{|c|}{ Transcription Factors } \\
\hline Forkhead box P3 & FOXP3 & GAAACAGCACA TTCCCAGAGT & GGATGAGGGTGGCA TAGGT & 90 & FJ491732.1 & 80.5 \\
\hline GATA transcription factor 3 & GATA3 & ATGAAACCGAAACCCGA TG & GAACACAGACACCACGGAAG & 100 & AB6121421 & 85.50 \\
\hline T-box transcription factor & T-bet & TACTACCGAAGCCAGGAAGC & AGAGTTCGCATGGAGTGGAA & 107 & DQ152994.1 & 85.5 \\
\hline \multicolumn{7}{|c|}{ Cell Marker / Receptor } \\
\hline Cluster of Differentiation 14 & CD 14 & CTCAGCGTGCTTGA TCTCAG & AAGGGATTTCCGTCCAGAGT & 98 & NM_001077209.1 & 83.5 \\
\hline Cluster of Differentiation 28 & $\operatorname{CD} 28$ & CTGTGGA GGTCTGTGCTGTG & GTCACTGTTTCATTGCCTACTTTC & 100 & AF092739 & 80 \\
\hline Chemokine receptor 3 & CXCR3 & GATGTGGGTGCTACTCA TGC & TCTCGGACCAGGATGAATCT & 107 & XM_004022179.1 & 87 \\
\hline Interleukin 4 Receptor a & ILARa & TGGGAAGAGACGGAGTTTTG & GCTTGGCA GGA TGTTTGTTT & 90 & XM_004020855 & 75 \\
\hline Mannose Receptor & MRC 1 & GGA GGGAACA CAAGGGATG & GCAAGGAAGGGTCA GGTTG & 94 & HM099914.1 & 78.5 \\
\hline Toll-like receptor 2 & TLR2 & CTCTTCCTGTTGCTCCTGCT & CTTCCTGGGCTTCCTCTTG & 108 & DQ890157.1 & 84.5 \\
\hline Toll-like receptor 4 & TLR4 & GGCATCATCTTCATCGTCCT & CCACTCCAGGTAGGTGTTCC & 99 & NM_001135930.1 & 825 \\
\hline WC.1 & WC.1 & ACAGCGGAAGTCTCAACACC & TCCAAGGGTCAGAAGGACAC & 120 & XM_004017139.1 & 81.5 \\
\hline \multicolumn{7}{|c|}{ Cytokines } \\
\hline Interferony & IFNY & ATGACCTGTCGCCAAAA TC & GCAGGCAGGAGAACCATTAC & 97 & NM_001009803.1 & 81 \\
\hline Insulin-like growth factor 1 & IGF 1 & TTCTATCTGGCCCTGTGCTT & ACTGGAGA GCA TCCA CCAAC & 94 & M31736.1 & 86.5 \\
\hline Interleukin $1 \beta$ & IL $1 \beta$ & GAAGGGAAGGGAAGAACACC & ACGAATACAGGGGAGGCAGT & 80 & NM_001009465.2 & 83 \\
\hline Interleukin 2 & IL2 & AGCTCCAAGCAAAAACCTGA & TTGTTTCAGATCCCTGTAGTTCC & 92 & NM_001009806 & 77.5 \\
\hline Interleukin 3 & IL 3 & GACACGACTTAGCAGCAGCA & GCTTCAGAGAGGGAACTAGGC & 94 & EU293838 & 77.5 \\
\hline Interleukin 4 & IL 4 & GCTGAACATCCTCACATCGAG & TTCTCAGTTGCGTTCTTGG & 87 & AF172168.1 & 80 \\
\hline Interleukin 5 & IL 5 & CACTGCTCTCCACGCATCAA & TCA TCAAGTTCCCATCA CCTA TCA & 50 & journal parasitology 2011 & 75 \\
\hline Interleukin 6 & IL 6 & TAACCACTCCAGCCACACAC & GA TAACCTTTGCGTTCTTTACCC & 80 & NM_0010093921 & 79.5 \\
\hline Interleukin 7 & IL7 7 & GCTCGAAAGTTGAA GCAA TTC & GTCAGTGTGCCCTGTGAAAC & 86 & U10089.1 & 78 \\
\hline Interleukin 8 & IL 8 & GGA TTCACGAGTTCCTGTTCA & CTGTGAGGTAGAAAGATGACTGAGA & 86 & NM_001009401.1 & 77 \\
\hline Interleukin 10 & IL 10 & TाTCCCTGACTGCCCTCTAA & GCTCCCTGGTTTCTCTTCCT & 105 & U11421.1 & 82 \\
\hline Interleukin $12 \beta$ & IL 12ß & ATTGAGGTCGTGATGGAAG & TGGTTTGA TGA TGTCCCTGA & 85 & AF209435.1 & 80 \\
\hline Interleukin 13 & IL 13 & ACTGGGGTTAGGAGGGACTG & A TGCCCACTGCTTAGTGCT & 85 & DQ679798.1 & 83 \\
\hline Interleukin 17 & IL 17 & GGAACACGAACTCCAGAAGG & ACTTGGCCTCCCAGATCAC & 114 & XM_004018887.1 & 82 \\
\hline Interleukin 25 & IL 25 & GAACCCACACCCTCTGTTTG & TTCCACTTCAGCCACTCCTC & 103 & NM_001195219.1 & 86.5 \\
\hline Transforming Growth Factor $\beta 1$ & TGF $\beta 1$ & GAACTGCTGTGTTCGTCAGC & AGAAATTGGCGTGGTAGCC & 92 & NM_001009400.1 & 81 \\
\hline Tumor Necrosis Factor & TNFa & GCCTGGCTCAGATGTGTIT & AAGCAAAAGGA GGCACAAAG & 90 & NM_001024860 & 81 \\
\hline \multicolumn{7}{|c|}{ Cell Recruitment } \\
\hline Complement component 3 & C3 & GCACTGTCCACCAACCTCA & A TCAGGCTTCTGCTTCTCCA & 87 & XM_004022821.1 & 81.5 \\
\hline Chemokine ligand 1 & $\mathrm{CXCL} 1$ & CCAGGCTAGTGCCAACTGAT & TGGGAGCCATTTGTTTCTCT & 102 & XM_004010090.1 & 78 \\
\hline Monocyte chemotactic Protein 1 & MCP1 & GACAAACTACAGGAGGTGAA TCTTG & TATCTGCGTGA TGGGGATG & 87 & NM_001009472 & 75.5 \\
\hline \multicolumn{7}{|c|}{$\begin{array}{rr}\text { Reference } \\
\end{array}$} \\
\hline Glyceraldehyde 3-phosphate dehydrogenase & GAPDH & CAGGAGCACGAGAGGAAGAG & AATGTATGGAGGTCGGGAGA & 91 & $\mathrm{HM} 043737$ & 83 \\
\hline
\end{tabular}



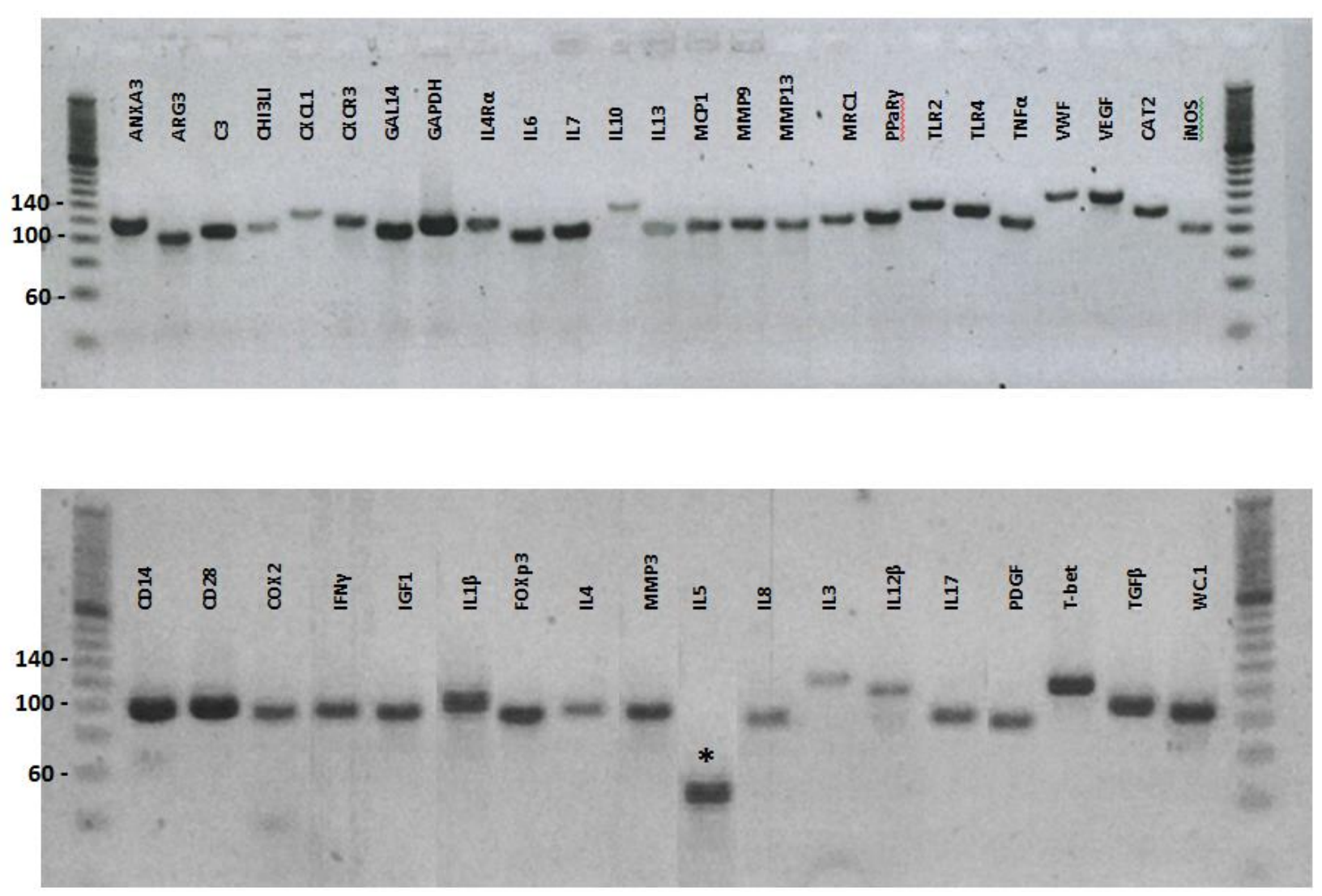

Figure 1: Primer validation gel electrophoresis

A 3\% agarose gel was used to validate primer amplicon length. Primers were designed to amplify $80-$ $120 \mathrm{bp}$. A specific primer for IL5 could not be designed; therefore a published primer was used (Robinson, et al., 2011). 

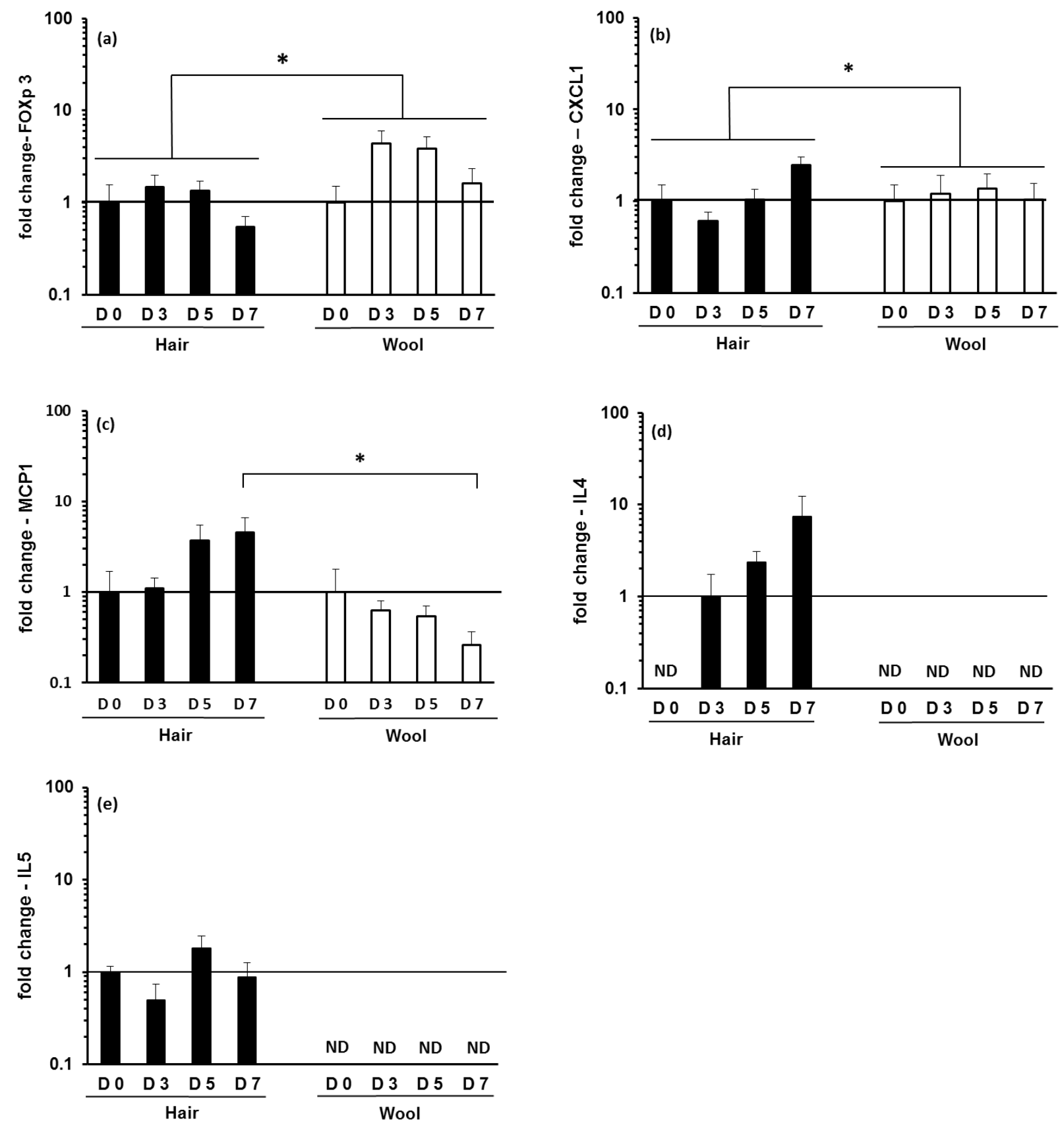

Figure 2: Gene expression in abomasal mucosa and lymph node 0, 3, 5, and 7 d.p.i.

qPCR analysis evaluated lymph node expression of FOXp3 (a) and mucosa expression of CXCL1, MCP1, IL4, and IL5 (b-e) of St. Croix (hair) and Crossbred (wool) lambs following an infection with 10,000 $\mathrm{H}$. contortus L3 larvae. A bar over all experimental days indicates a significant effect of type. Statistical 
analyses were performed on log 2 of the $\Delta C$ t values. Graphs based on fold change from day 0 control animals. ND $=$ No Detection

$* P<0.05, * * P<0.01, * * * P<0.001$

Table 2a: qPCR gene expression analysis of abomasal fold tissue experiment 1

Tissues of hair and wool animals $0,3,5$, and 7 days post $H$. contortus infection. Table represents average fold change across all time points for each breed type. Significance based on log $(\Delta \mathrm{Ct}, 2)$.

\begin{tabular}{lcc}
\hline & \multicolumn{2}{c}{ Days 0-7 } \\
\cline { 2 - 2 } & Hair & Wool \\
\hline \hline MCP1 & ++ \\
\hline MMP13 & +++ \\
\hline PDGF & + \\
\hline TNFa & ++ \\
\hline$+P<0.05,++P<0.01,+++$ & $P<0.001$
\end{tabular}

Table 2b: qPCR gene expression analysis of abomasal mucosa tissue experiment $1 \& 2$

Tissues of hair and wool animals $0,3,5,7$, and 10 days post $H$. contortus infection. Table represents average fold change across all time points for each breed type. Significance based on log $(\Delta \mathrm{Ct}, 2)$.

\begin{tabular}{|c|c|c|c|c|}
\hline & \multicolumn{2}{|c|}{ Days 0-7 } & \multicolumn{2}{|c|}{ Day 10} \\
\hline & Hair & Wool & Hair & Wool \\
\hline ANXA3 & & ++ & & ++ \\
\hline ARG1 & + & & & + \\
\hline GAL14 & + & & & + \\
\hline MMP13 & & & & + \\
\hline PPaRy & & + & & \\
\hline VEGF & & ++ & & ++ \\
\hline IL3 & & ++ & & \\
\hline IL6 & & ++ & & \\
\hline TNF $\alpha$ & & ++ & & \\
\hline CXCR3 & & ++ & & \\
\hline$\underline{I L} 4 R \alpha$ & & & & + \\
\hline WC.1 & & + & & \\
\hline $\mathrm{C} 3$ & & ++ & & \\
\hline
\end{tabular}


$1^{\circ}$ Hair $\quad 1^{\circ}$ Wool

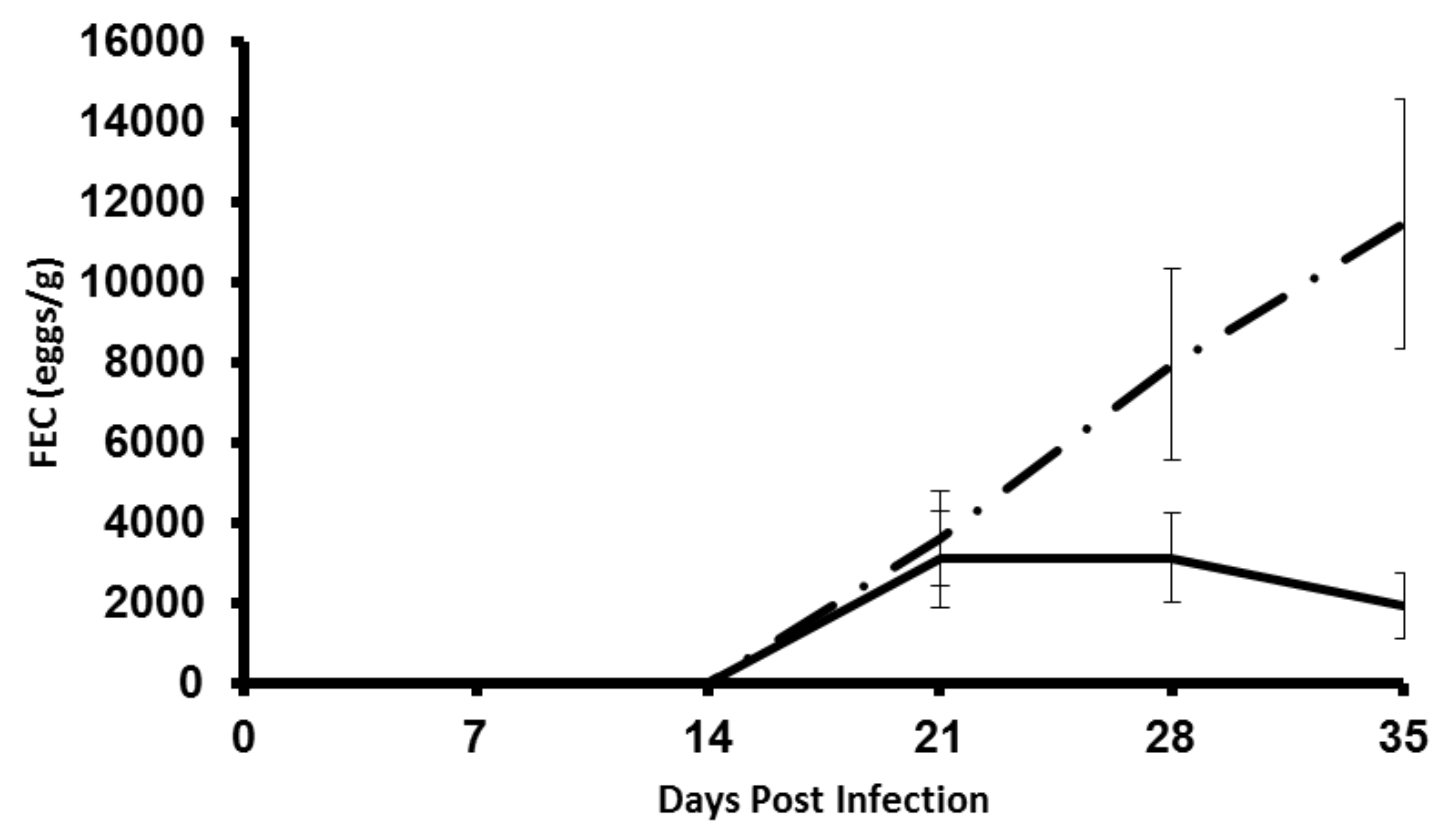

Figure 3: Fecal Egg Count primary infection.

Weekly fecal samples were collected from St. Croix (hair) and Crossbred Suffolk (wool) lambs for 5 weeks during a primary infection with 10,000 L3 H. contortus larvae. Naïve animals remained uninfected. All animals received anthelmintic treatment on day 35 post infection. Data were log transformed for statistical analysis and backtransformed for the reporting of means. 

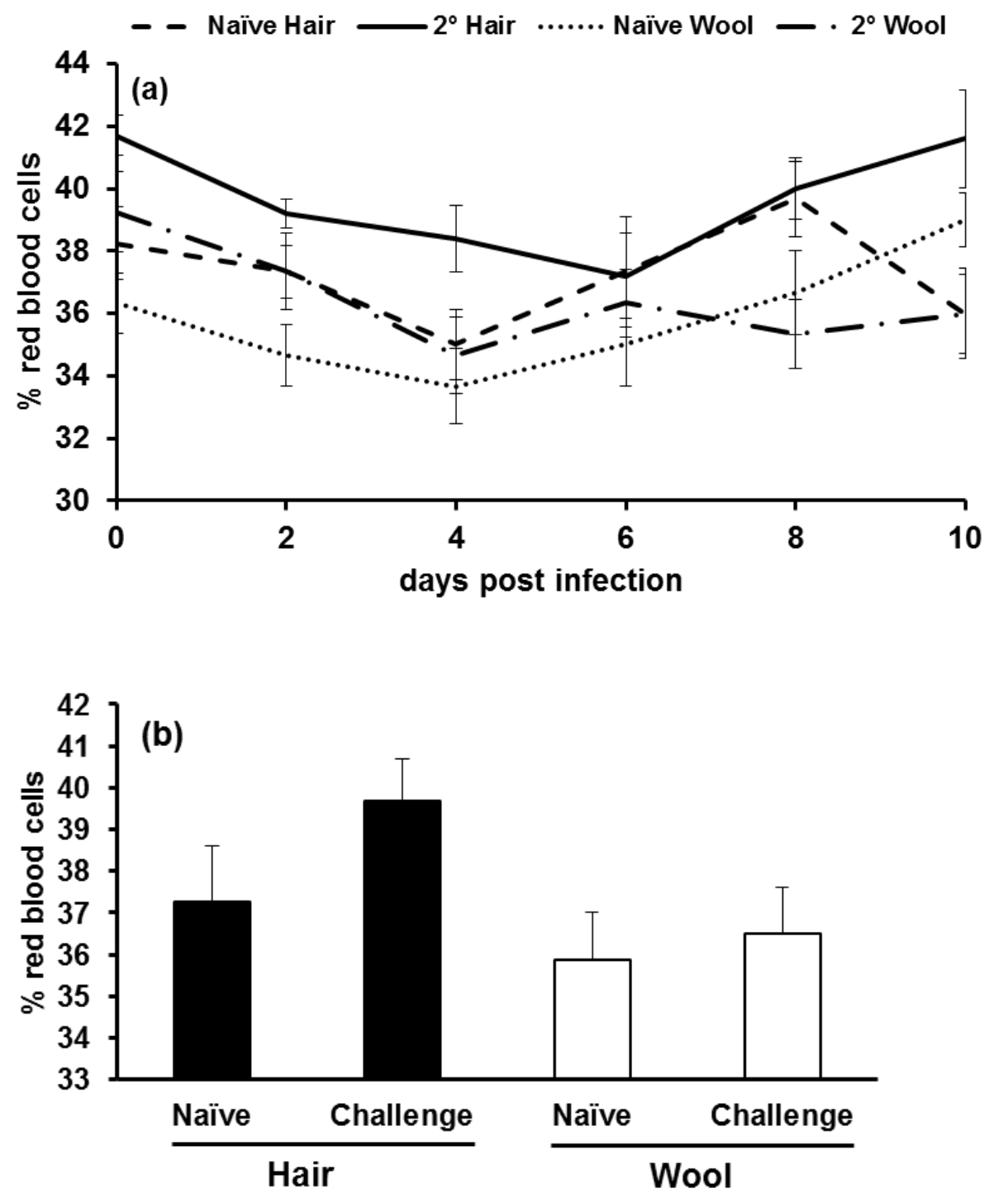

Figure 4: Packed Cell Volume (PCV) during 10 day challenge infection

Packed cell volume of St. Croix (hair) and Crossbred Suffolk (wool) lambs were collected every two days post challenge infection (a). Average PCV of hair and wool animals for duration of challenge infection (b). 

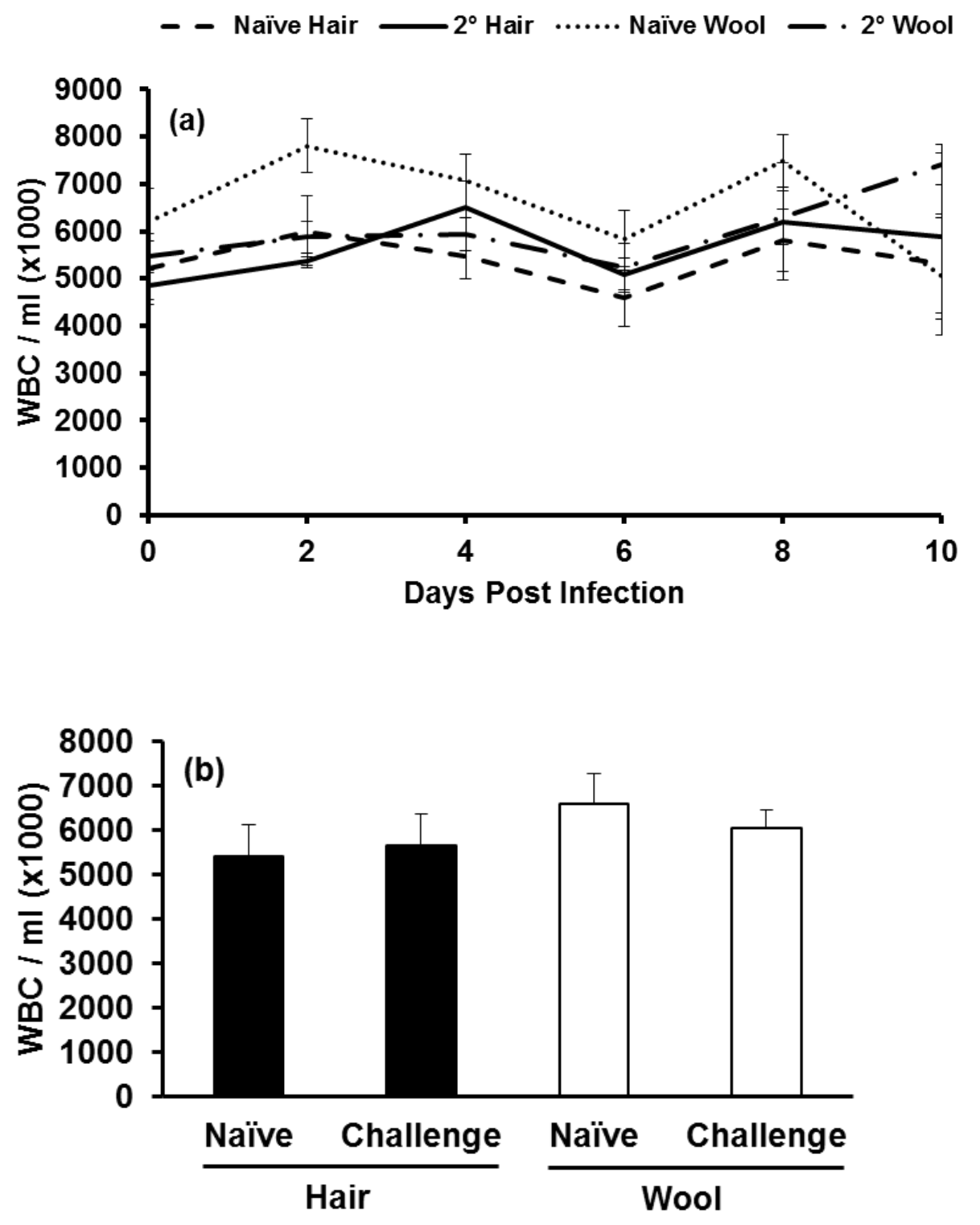

Figure 5: White blood cell (WBC) count during 10 day challenge infection.

Total WBC of St. Croix hair and Crossbred Suffolk wool animals were performed every two days post challenge infection (a). Average WBC of hair and wool animals for duration of challenge infection (b). 

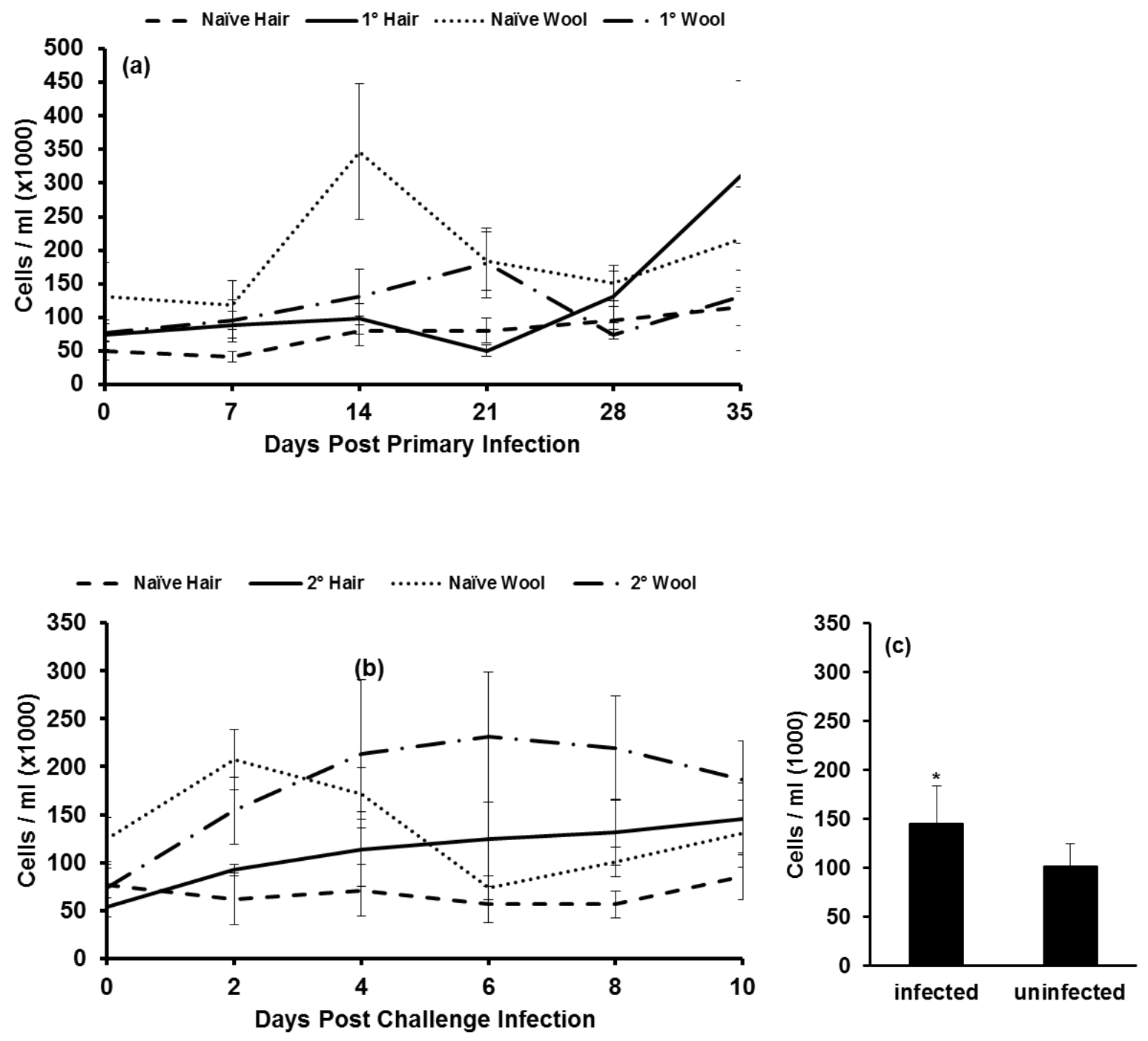

Figure 6: Circulating eosinophil counts during primary and 10 day challenge infection

Eosinophils stained with Phloxine B were enumerated during primary (a) and challenge $H$. contortus infections (b). Whole blood samples for primary infection were collected weekly until anthelmintic treatment on day 35 (a) and blood samples were collected every 2 days during the 10 day challenge infection (b). Average eosinophils for infected and uninfected animals during challenge infection (c). $* P<0.05$ 


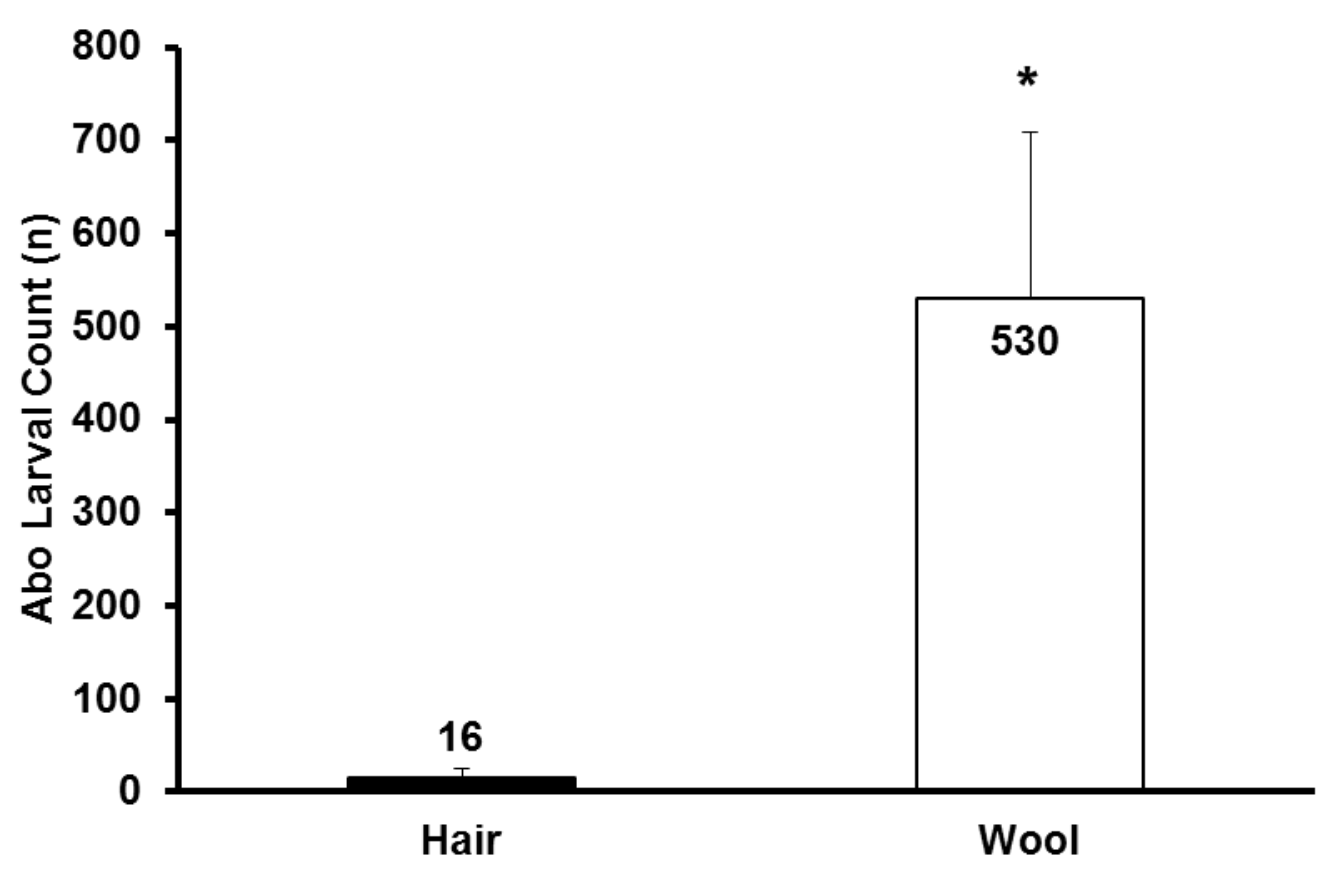

Figure 7: Total worm burden 10 days post challenge infection

Worms collected at day 10 and enumerated from both $10 \%$ aliquot of the abomasum content and abomasum soak fluid. Abomasal soak parasites were collected from soaking one half of the abomasum overnight in water. All counts are a sum of parasites found in the abomasum aliquot multiplied by 10 and total parasites collected from the abomasum soak solution.

$* P<0.05$ 

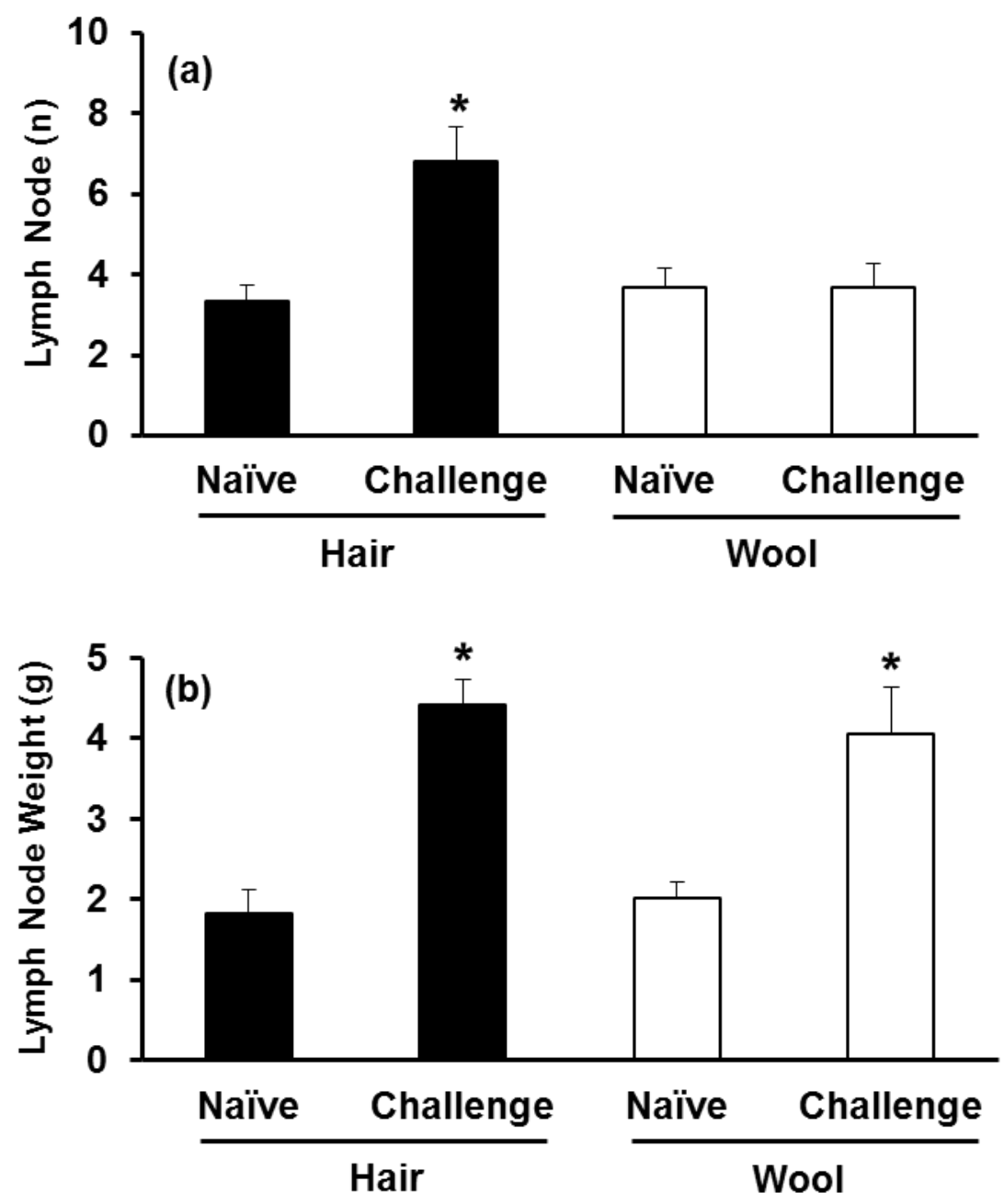

Figure 8: Abomasal lymph node development 10 days post challenge infection

All palpable lymph nodes from the lesser omentum of each animal were collected, counted (a), and weighed (b). $* P<0.05$ 


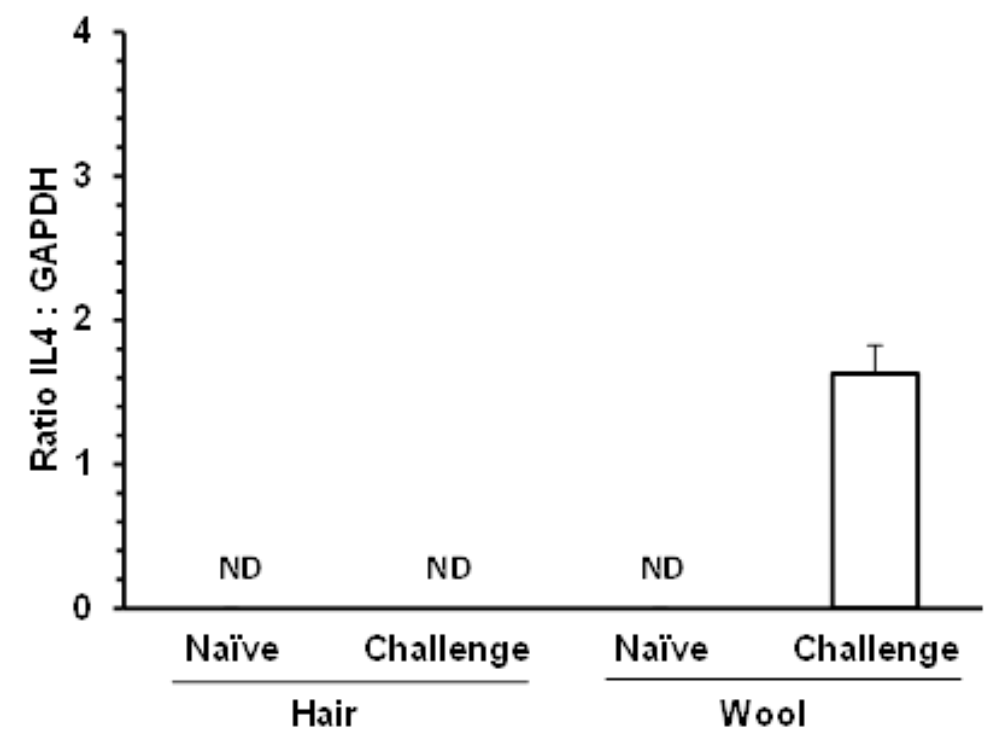

Figure 9: qPCR analysis of mucosa IL4 expression 10 days post challenge infection

There was no detection (ND) of IL 4 in hair animals from experiment 2, so graph represents expression challenge wool animals from experiment 2 as a ratio of IL4 expression to GAPDH expression. 


\section{Discussion}

Many studies have been conducted to evaluate gene expression of parasite resistant sheep (Diez-Tascón et al., 2005; Pernthaner et al., 2005; Keane et al., 2006; MacKinnon, 2007; MacKinnon et al., 2009; Andronicos et al., 2010). Their focus has been primarily on the later stages of infection when worm burden can be evaluated by FEC. The two experiments conducted in this thesis aimed to evaluate expression of 46 candidate genes in parasite resistant (hair) and susceptible (wool) sheep during early (days $0-7$ ) and late (day 10) larval stages of challenge $H$. contortus infections. Forty-six candidate genes were selected to better characterize immune mechanisms involved in enhanced resistance to gastrointestinal parasite infection.

Gene expression of wool animals during the first seven days of infection support a response that is typical of damage caused done by invading parasites. Vascular endothelial growth factor (VEGF) and platelet derived growth factor (PDGF) both play roles in angiogenesis (Benjamin et al., 1998). Peroxisome proliferator- activated receptor- $\gamma(\mathrm{PPaR} \gamma)$ has roles in adipogenesis and matrix metalloproteinase 13 (MMP13) is produced in remodeling tissues. The host's response to tissue damage is further intensified by increased expression of the inflammatory cytokines, tumor necrosis factor- $\alpha$ (TNF $\alpha$ ) and interleukin-6 (IL6). Annexin 3 (ANXA3) production may also enhance inflammation as it is associated with granule fusion and degranulation (Le Cabec and Maridonneau-Parini, 1994).

The response lacking in the wool animals is an indication of the expected T-helper type 2 $\left(\mathrm{Th}_{2}\right)$ immune response, known to be involved in host protective immune responses to helminth 
parasites. There was no detection of IL4 or IL5 in the mucosa of these animals by day 7. Wool animals did express more IL3, which is a cytokine that stimulates production of myeloid progenitor cells, MCP1 in the abomasal fold. These genes along with an increase in complement component 3 (C3) are indicative of innate cell signaling and innate immunity. One possible explanation for lack of $T_{2}$-type immune responses of wool sheep is both the existence of inflammatory responses found at the local site of infection and increased expression of forkhead box P3 (FOXp3) in the lymph node. FOXp3 is a transcription factor that is essential for T-regulatory $\left(T_{\text {reg }}\right)$ cell differentiation. The sub populations of T-cells are antagonistic of each other and production of each type are dependent on the cytokine environment in the lymph node (Zhu et al., 2006; Dardalhon et al., 2008). T-regulatory cell production can suppress $\mathrm{Th}_{2}$ cell and cytokine production. Therefore, during the first seven days of infection the suppression of $\mathrm{Th}_{2}$ immunity may have resulted from immunosuppression originating in the local draining lymph nodes.

Early expression of IL4 and IL5 in mucosa tissue in hair animals indicates targeted expression of critical $\mathrm{Th}_{2}$ cytokines at the host-parasite interface. This was expected and is consistent with other studies that report $\mathrm{Th}_{2}$ immune responses in animals that are resistant to H. contortus (Gill et al., 2000; Lacroux et al., 2006). The source of early IL4 production cannot be definitively determined from our experiment, however, the physiological data reported an influx of neutrophils to mucosal tissue in hair animals, which is paralleled by up-regulation of chemokine ligand 1 (CXCL1), a neutrophil chemoattractant. Neutrophils can produce IL4 (Brandt et al., 2000), thus evidence exists that neutrophils may be participating in IL4 production prior to the generation of Th2 cells. Further support for an early $\mathrm{Th}_{2}$ immune environment is 
increased expression of arginase 1 (ARG1). Arginase production suggests that monocytes, being recruited by an increase of monocyte chemotactic protein 1 (MCP1), are shifting their differentiation towards an alternatively activated macrophage (M2) phenotype. This phenotype is more closely associated with wound healing and down regulating inflammation (Kreider et al., 2007).

Our experiment also indicates that eosinophils are associated with immune responses generated by parasite resistant sheep during the first seven days of infection by the production of IL5 and galectin-14 (GAL14). Galectin-14 is uniquely expressed by ovine eosinophils following parasite challenge (Young et al., 2009) and IL-5 was originally discovered as an eosinophil colony-stimulating factor and is a major regulator of eosinophil accumulation in tissues (Lopez et al., 1986).

The first seven days of $H$. contortus infection focuses on recognition of larval parasites as they enter the abomasum and start feeding on blood. By day 14, the parasites that have reached the abomasum should have developed into reproductively active adults. Genes being expressed in experiment 1 , indicate the production of protective immune responses early in parasite resistant animals. Other studies show that more susceptible breeds of sheep do produce a protective response latter on in the infection (days 15 and 28) (Lacroux et al., 2006). Evaluation of gene expression on day ten post challenge infection resulted in no up-regulation of any candidate genes in the hair animals is an important finding as worm burden was essentially diminished. 
Genes found to be up-regulated in hair animals during experiment 1, ARG1 and GAL-14, are being up-regulated in wool animals by day ten. There is also mucosal expression of IL4 and its receptor (IL4R $\alpha$ ) on day ten. The first indication of the expected $\mathrm{Th}_{2}$ environment in the hair animals took place on day 3 of experiment 1 . Wool animal IL4 expression was not seen until day 10. This is a 7 day delay in immune response to the parasite and perhaps permitted parasite establishment in the abomasum. Ultimately, an early IL4-mediated immune response is a candidate mechanism of parasite resistance in sheep. 


\section{Literature Cited}

Abbott, K., M. Taylor, and L. Stubbings. 2004. Sustainable worm control strategies for sheep. A technical manual for veterinary surgeons and advisers. Sustainable Control of Parasites in Sheep (SCOPS) eds.

Amarante, A., T. Craig, W. Ramsey, S. Davis, and F. Bazer. 1999. Nematode burdens and cellular responses in the abomasal mucosa and blood of Florida Native, Rambouillet and crossbreed lambs. Veterinary parasitology 80: 311-324.

Anderson, T., M. Blouin, and R. Beech. 1998. Population biology of parasitic nematodes: applications of genetic markers. Advances in parasitology 41: 219-283.

Andronicos, N., P. Hunt, and R. Windon. 2010. Expression of genes in gastrointestinal and lymphatic tissues during parasite infection in sheep genetically resistant or susceptible to Trichostrongylus colubriformis and Haemonchus contortus. International journal for parasitology 40: 417-429.

Anthony, R. et al. 2006. Memory T(H)2 cells induce alternatively activated macrophages to mediate protection against nematode parasites. Nature medicine 12: 955-960.

Balic, A., V. Bowles, and E. Meeusen. 2002. Mechanisms of immunity to Haemonchus contortus infection in sheep. Parasite immunology 24: 39-46.

Benjamin, L., I. Hemo, and E. Keshet. 1998. A plasticity window for blood vessel remodelling is defined by pericyte coverage of the preformed endothelial network and is regulated by PDGF-B and VEGF. Development (Cambridge, England) 125: 1591-1598.

Blouin, M., C. Yowell, C. Courtney, and J. Dame. 1995. Host movement and the genetic structure of populations of parasitic nematodes. Genetics 141: 1007-1014.

Bowdridge, S., K. MacKinnon, J. McCann, A. Zajac, and D. Notter. 2013. Hair-type sheep generate an accelerated and longer-lived humoral immune response to Haemonchus contortus infection. Veterinary parasitology 196: 172-178.

Brandt, E., G. Woerly, A. B. Younes, S. Loiseau, and M. Capron. 2000. IL-4 production by human polymorphonuclear neutrophils. Journal of leukocyte biology 68: 125-130.

Burke, J. M., and J. E. Miller. 2004. Relative resistance to gastrointestinal nematode parasites in Dorper, Katahdin, and St. Croix lambs under conditions encountered in the southeastern region of the United States. Small Ruminant Research 54.

Castillo, J. et al. 2011. Association between major histocompatibility complex microsatellites, fecal egg count, blood packed cell volume and blood eosinophilia in Pelibuey sheep infected with Haemonchus contortus. Veterinary parasitology 177: 339-344. 
Chilton, N., F. Huby-Chilton, R. Gasser, and I. Beveridge. 2006. The evolutionary origins of nematodes within the order Strongylida are related to predilection sites within hosts. Molecular phylogenetics and evolution 40: 118-128.

Coles, G. 2005. Anthelmintic resistance--looking to the future: a UK perspective. Research in veterinary science 78: 99-108.

Coles, G. et al. 1992. World Association for the Advancement of Veterinary Parasitology (W.A.A.V.P.) methods for the detection of anthelmintic resistance in nematodes of veterinary importance. Veterinary parasitology 44: 35-44.

Coles, G. et al. 2006. The detection of anthelmintic resistance in nematodes of veterinary importance. Veterinary parasitology 136: 167-185.

Colvin, A., S. Walkden-Brown, and M. Knox. 2012. Role of host and environment in mediating reduced gastrointestinal nematode infections in sheep due to intensive rotational grazing. Veterinary parasitology 184: 180-192.

Coop, R., and I. Kyriazakis. 1999. Nutrition-parasite interaction. Veterinary parasitology 84: 187204.

Courtney, C., C. Parker, K. McClure, and R. Herd. 1985. Resistance of exotic and domestic lambs to experimental infection with Haemonchus contortus. International journal for parasitology 15: 101-109.

Dardalhon, V. et al. 2008. IL-4 inhibits TGF-beta-induced Foxp3+ T cells and, together with TGFbeta, generates IL-9+ IL-10+ Foxp3(-) effector T cells. Nature immunology 9: 1347-1355.

Diez-Tascón, C. et al. 2005. Microarray analysis of selection lines from outbred populations to identify genes involved with nematode parasite resistance in sheep. Physiological genomics 21: 59-69.

Dominik, S. 2005. Quantitative trait loci for internal nematode resistance in sheep: a review. Genetics, selection, evolution : GSE 37 Suppl 1: 96.

Donald, A., and P. Waller. 1973. Gastro-intestinal nematode parasite populations in ewes and lambs and the origin and time course of infective larval availability in pastures. International journal for parasitology 3: 219-233.

Gamble, H., and A. Zajac. 1992. Resistance of St. Croix lambs to Haemonchus contortus in experimentally and naturally acquired infections. Veterinary parasitology 41: 211-225.

Geary, T., and D. Thompson. 2001. Caenorhabditis elegans: how good a model for veterinary parasites? Veterinary parasitology 101: 371-386.

Gill, H. 1991. Genetic control of acquired resistance to haemonchosis in Merino lambs. Parasite immunology 13: 617-628.

Gill, H. 1994. Cell-mediated immunity in Merino lambs with genetic resistance to Haemonchus contortus. International journal for parasitology 24: 749-756. 
Gill, H., K. Altmann, M. Cross, and A. Husband. 2000. Induction of T helper 1- and T helper 2type immune responses during Haemonchus contortus infection in sheep. Immunology 99: 458-463.

Gill, H., D. Watson, and M. Brandon. 1993. Monoclonal antibody to CD4+ T cells abrogates genetic resistance to Haemonchus contortus in sheep. Immunology 78: 43-49.

Gratchev, A., K. Schledzewski, P. Guillot, and S. Goerdt. 2001. Alternatively activated antigenpresenting cells: molecular repertoire, immune regulation, and healing. Skin pharmacology and applied skin physiology 14: 272-279.

Gray, G. 1997. The use of genetically resistant sheep to control nematode parasitism. Veterinary parasitology 72: 345.

Hesse, M. et al. 2001. Differential regulation of nitric oxide synthase-2 and arginase-1 by type 1/type 2 cytokines in vivo: granulomatous pathology is shaped by the pattern of Larginine metabolism. Journal of immunology (Baltimore, Md. : 1950) 167: 6533-6544.

Hohenhaus, M., and P. Outteridge. 1995. The immunogenetics of resistance to Trichostrongylus colubriformis and Haemonchus contortus parasites in sheep. The British veterinary journal 151: 119-140.

Hooda, V., C. Yadav, S. Chaudhri, and B. Rajpurohit. 1999. Variation in resistance to haemonchosis: selection of female sheep resistant to Haemonchus contortus. Journal of helminthology 73: 137-142.

Jabbar, A. et al. 2006. Anthelmintic resistance: the state of play revisited. Life sciences 79: 24132431.

Jacobs, H., K. Ashman, and E. Meeusen. 1995. Humoral and cellular responses following local immunization with a surface antigen of the gastrointestinal parasite Haemonchus contortus. Veterinary immunology and immunopathology 48: 323-332.

Kaminsky, R. et al. 2008. A new class of anthelmintics effective against drug-resistant nematodes. Nature 452: 176-180.

Kaplan, R. 2004. Drug resistance in nematodes of veterinary importance: a status report. Trends in parasitology 20: 477-481.

Kaplan, R. et al. 2004. Validation of the FAMACHA eye color chart for detecting clinical anemia in sheep and goats on farms in the southern United States. Veterinary parasitology 123: 105-120.

Keane, O. et al. 2006. Gene expression profiling of naïve sheep genetically resistant and susceptible to gastrointestinal nematodes. BMC genomics 7: 42.

Knox, D., D. Redmond, P. Skuce, and G. Newlands. 2001. The contribution of molecular biology to the development of vaccines against nematode and trematode parasites of domestic ruminants. Veterinary parasitology 101: 311-335.

Kolaczkowska, E., and P. Kubes. 2013. Neutrophil recruitment and function in health and inflammation. Nature reviews. Immunology 13: 159-175. 
Kreider, T., R. Anthony, J. Urban, and W. Gause. 2007. Alternatively activated macrophages in helminth infections. Current opinion in immunology 19: 448-453.

Lacroux, C. et al. 2006. Haemonchus contortus (Nematoda: Trichostrongylidae) infection in lambs elicits an unequivocal Th2 immune response. Veterinary research 37: 607-622.

Lauren, J. O. C., W. W.-B. Stephen, and P. K. Lewis. 2006. Ecology of the free-living stages of major trichostrongylid parasites of sheep. Veterinary parasitology 142.

Laurenson, Y., S. Bishop, A. Forbes, and I. Kyriazakis. 2013. Modelling the short- and long-term impacts of drenching frequency and targeted selective treatment on the performance of grazing lambs and the emergence of anthelmintic resistance. Parasitology 140: 780-791.

Le Cabec, V., and I. Maridonneau-Parini. 1994. Annexin 3 is associated with cytoplasmic granules in neutrophils and monocytes and translocates to the plasma membrane in activated cells. The Biochemical journal 303 ( Pt 2): 481-487.

Livak, K., and T. Schmittgen. 2001. Analysis of relative gene expression data using real-time quantitative PCR and the 2(-Delta Delta C(T)) Method. Methods (San Diego, Calif.) 25: 402-408.

Lopez, A. et al. 1986. Murine eosinophil differentiation factor. An eosinophil-specific colonystimulating factor with activity for human cells. The Journal of experimental medicine 163: 1085-1099.

MacKinnon, K. 2007. Differential gene expression and immune regulatory mechanisms in parasite-resistant hair and susceptible wool sheep infected with the parasitic ....

MacKinnon, K., J. Burton, A. Zajac, and D. Notter. 2009. Microarray analysis reveals difference in gene expression profiles of hair and wool sheep infected with Haemonchus contortus. Veterinary immunology and immunopathology 130: 210-220.

Marshall, K. et al. 2009. Genetic mapping of quantitative trait loci for resistance to Haemonchus contortus in sheep. Animal genetics 40: 262-272.

Meeusen, E., A. Balic, and V. Bowles. 2005. Cells, cytokines and other molecules associated with rejection of gastrointestinal nematode parasites. Veterinary immunology and immunopathology 108: 121-125.

Miller, H. 1996. Prospects for the immunological control of ruminant gastrointestinal nematodes: natural immunity, can it be harnessed? International journal for parasitology 26: 801-811.

Miller, J., and D. Horohov. 2006. Immunological aspects of nematode parasite control in sheep. Journal of animal science 84 Suppl: 32.

Mugambi, J. et al. 1997. Resistance of four sheep breeds to natural and subsequent artificial Haemonchus contortus infection. Veterinary parasitology 69: 265-273.

Notter, D., S. Andrew, and A. Zajac. 2003. Responses of hair and wool sheep to a single fixed dose of infective larvae of $<\mathrm{i}>$ Haemonchus contortus $</ i>$. Small Ruminant Research. 
Outteridge, P. et al. 1996. The PCR typing of MHC-DRB genes in the sheep using primers for an intronic microsatellite: application to nematode parasite resistance. Immunology and cell biology 74: 330-336.

Peña, M., J. Miller, and D. Horohov. 2006. Effect of CD4+ T lymphocyte depletion on resistance of Gulf Coast Native lambs to Haemonchus contortus infection. Veterinary parasitology 138: $240-246$.

Pernthaner, A., S.-A. Cole, L. Morrison, and W. Hein. 2005. Increased expression of interleukin-5 (IL-5), IL-13, and tumor necrosis factor alpha genes in intestinal lymph cells of sheep selected for enhanced resistance to nematodes during infection with Trichostrongylus colubriformis. Infection and immunity 73: 2175-2183.

Pernthaner, A. et al. 1995. The immune responsiveness of Romney sheep selected for resistance or susceptibility to gastrointestinal nematodes: Iymphocyte blastogenic activity, eosinophilia and total white blood cell counts. International journal for parasitology 25: 523-529.

Pfeffer, A. et al. 1996. Sequential cellular and humoral responses in the abomasal mucosa and blood of Romney sheep dosed with Trichostrongylus axei. International journal for parasitology 26: 765-773.

Pickering, N. et al. 2012. Genetic parameters for production traits in New Zealand dual-purpose sheep, with an emphasis on dagginess. Journal of animal science 90: 1411-1420.

Rainbird, M., D. Macmillan, and E. Meeusen. 1998. Eosinophil-mediated killing of Haemonchus contortus larvae: effect of eosinophil activation and role of antibody, complement and interleukin-5. Parasite immunology 20: 93-103.

Riley, D., and J. Van Wyk. 2009. Genetic parameters for FAMACHA score and related traits for host resistance/resilience and production at differing severities of worm challenge in a Merino flock in South Africa. Veterinary parasitology 164: 44-52.

Robinson, N., D. Piedrafita, K. Snibson, P. Harrison, and E. Meeusen. 2010. Immune cell kinetics in the ovine abomasal mucosa following hyperimmunization and challenge with Haemonchus contortus. Veterinary research 41: 37.

Roeber, F., A. Jex, and R. Gasser. 2013. Impact of gastrointestinal parasitic nematodes of sheep, and the role of advanced molecular tools for exploring epidemiology and drug resistance - an Australian perspective. Parasites \& vectors 6: 153.

Saddiqi, H. et al. 2011. Small ruminant resistance against gastrointestinal nematodes: a case of Haemonchus contortus. Parasitology research 109: 1483-1500.

Saluja, R., M. Metz, and M. Maurer. 2012. Role and relevance of mast cells in fungal infections. Frontiers in immunology 3: 146.

Shakya, K., J. Miller, L. Lomax, and D. Burnett. 2011. Evaluation of immune response to artificial infections of Haemonchus contortus in Gulf Coast Native compared with Suffolk lambs. Veterinary parasitology 181: 239-247. 
Sissay, M., A. Asefa, A. Uggla, and P. Waller. 2006. Anthelmintic resistance of nematode parasites of small ruminants in eastern Ethiopia: exploitation of refugia to restore anthelmintic efficacy. Veterinary parasitology 135: 337-346.

Stear, M., and M. Murray. 1994. Genetic resistance to parasitic disease: particularly of resistance in ruminants to gastrointestinal nematodes. Veterinary parasitology 54: 161176.

van Wyk, J., and G. Bath. 2002. The FAMACHA system for managing haemonchosis in sheep and goats by clinically identifying individual animals for treatment. Veterinary research 33: 509-529.

Vanimisetti, H., S. Greiner, A. Zajac, and D. Notter. 2004. Performance of hair sheep composite breeds: resistance of lambs to Haemonchus contortus. Journal of animal science 82: 595-604.

Veglia, F. 1916. The anatomy and life-history of Haemonchus contortus (Rud.). Pretoria: Government Printer and Stationery Office.

Velnar, T., T. Bailey, and V. Smrkolj. 2009. The wound healing process: an overview of the cellular and molecular mechanisms. The Journal of international medical research 37: 1528-1542.

Wildeus, S. 1997. Hair sheep genetic resources and their contribution to diversified small ruminant production in the United States. Journal of animal science 75: 630-640.

Windon, R. 1996. Genetic control of resistance to helminths in sheep. Veterinary immunology and immunopathology 54: 245-254.

Yazwinski, T., L. Goode, D. Moncol, G. Morgan, and A. Linnerud. 1979. Parasite resistance in straightbred and crossbred Barbados Blackbelly sheep. Journal of animal science 49: 919-926.

Young, A. et al. 2009. Functional characterization of an eosinophil-specific galectin, ovine galectin-14. Glycoconjugate journal 26: 423-432.

Zajac, A., S. Krakowka, R. Herd, and K. McClure. 1990. Experimental Haemonchus contortus infection in three breeds of sheep. Veterinary parasitology 36: 221-235.

Zhu, J., H. Yamane, J. Cote-Sierra, L. Guo, and W. Paul. 2006. GATA-3 promotes Th2 responses through three different mechanisms: induction of Th2 cytokine production, selective growth of Th2 cells and inhibition of Th1 cell-specific factors. Cell research 16: 3-10. 